\title{
Cyanometallate-Bridged Didysprosium Single-Molecule Magnets Constructed with Single-lon-Magnet Building Block
}

\author{
Yang Liu, Yan-Cong Chen, Jiang Liu, Wen-Bin Chen, Guo-Zhang Huang, Si-Guo Wu, Jin Wang, \\ Jun-Liang Liu, ${ }^{*}$ and Ming-Liang Tong \\ MOE Key Lab of Bioinorganic and Synthetic Chemistry, School of Chemistry, Sun Yat-Sen University, \\ Guangzhou 510275, P. R. China \\ *E-mail: liujliang5@mail.sysu.edu.cn
}

\section{Contents}

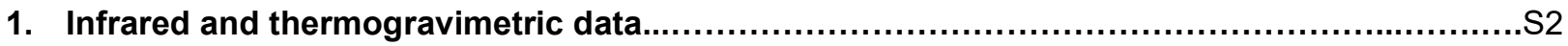

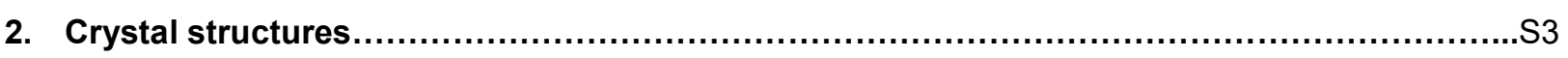

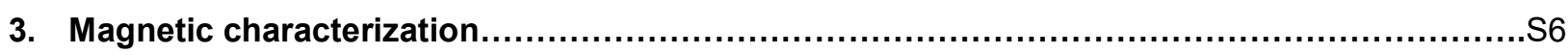

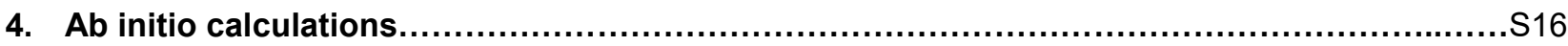

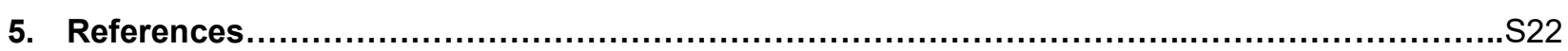




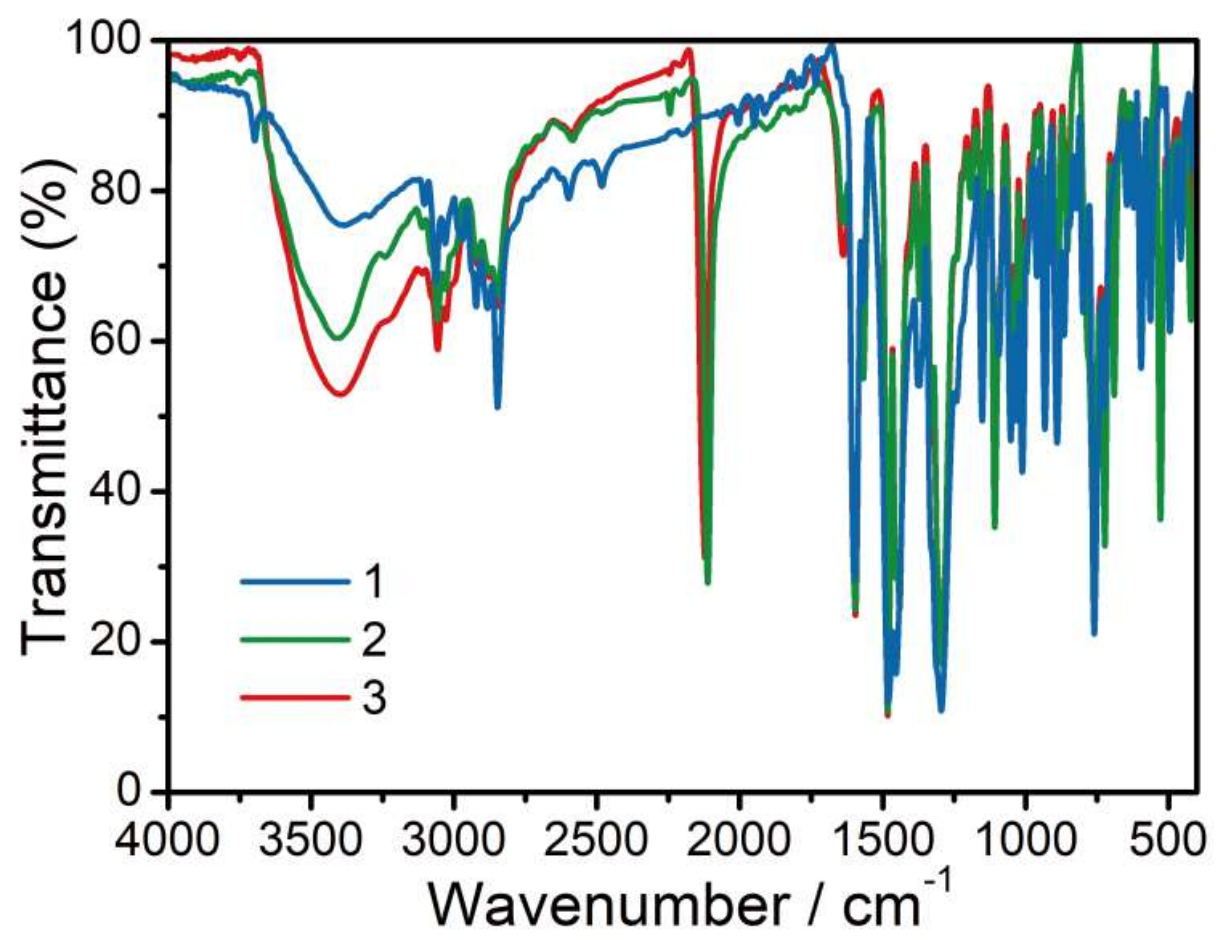

Figure S1. Infrared spectra for 1 (blue), 2 (green) and 3 (red). The IR spectrum displays a strong vCN stretching band centered at $2111 \mathrm{~cm}^{-1}$ (vs) for 2 and $2121 \mathrm{~cm}^{-1}$ (vs) for 3 .
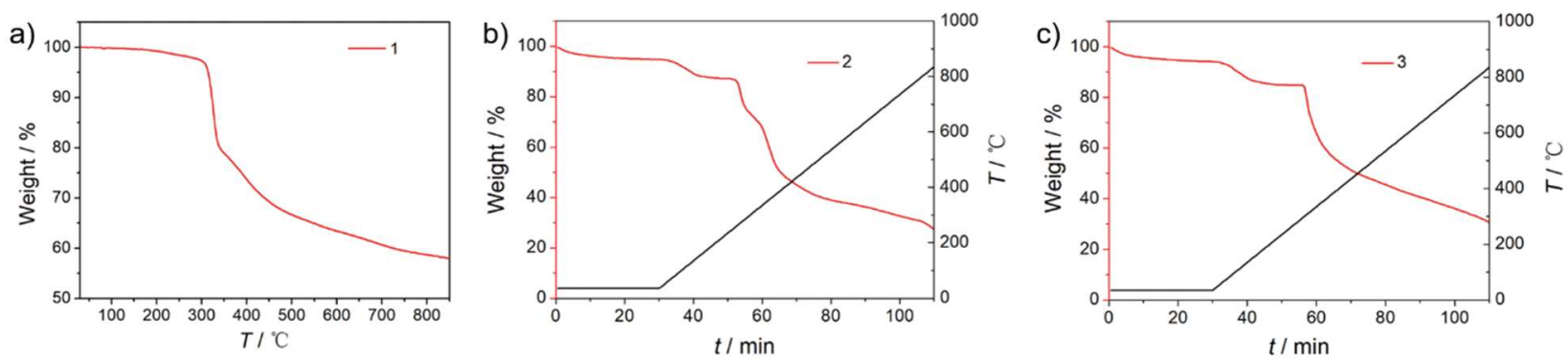

Figure S2. Thermogravimetric analysis for $\mathbf{1}$ (a), 2 (b) and $\mathbf{3}$ (c) under $\mathrm{N}_{2}$ atmosphere, where b and c show complexes $\mathbf{2}$ and $\mathbf{3}$ are easy to lost solvent even at room temperature, where complexes $\mathbf{2}$ and $\mathbf{3}$ undergo an additional constant temperature segment at room temperature which is different from complex 1 . Figures $b$ and c show that complexes $\mathbf{2}$ and $\mathbf{3}$ are easy to lost solvent even at room temperature. 
Table S1. Selected bond lengths $(\AA)$ and bond angles $\left(^{\circ}\right)$ for 1, 2 and 3.

\begin{tabular}{|c|c|c|c|c|c|}
\hline Bond & \multicolumn{2}{|c|}{1} & Bond angle & \multicolumn{2}{|l|}{1} \\
\hline Dy1-N2 & \multicolumn{2}{|c|}{$2.538(4)$} & N2-Dy1-N3 & \multicolumn{2}{|c|}{$66.46(13)$} \\
\hline Dy1-N2A & \multicolumn{2}{|c|}{$2.538(4)$} & N2-Dy1-N2A & \multicolumn{2}{|c|}{$157.21(19)$} \\
\hline Dy1-N3 & \multicolumn{2}{|c|}{$2.540(4)$} & N2-Dy1-N3A & \multicolumn{2}{|c|}{$136.12(12)$} \\
\hline Dy1-N3A & \multicolumn{2}{|c|}{$2.540(4)$} & N2-Dy1-O2 & \multicolumn{2}{|c|}{$80.22(13)$} \\
\hline Dy1-O2 & \multicolumn{2}{|c|}{$2.470(4)$} & N2-Dy1-O2A & \multicolumn{2}{|c|}{$79.29(13)$} \\
\hline Dy1-O2A & \multicolumn{2}{|c|}{$2.470(4)$} & N2-Dy1-O3 & \multicolumn{2}{|c|}{$98.17(13)$} \\
\hline Dy1-O3 & \multicolumn{2}{|c|}{$2.173(3)$} & N2-Dy1-O3A & \multicolumn{2}{|c|}{$86.77(12)$} \\
\hline \multirow[t]{15}{*}{ Dy1-03A } & \multicolumn{2}{|c|}{$2.173(3)$} & N3-Dy1-N2A & \multicolumn{2}{|c|}{$136.12(12)$} \\
\hline & & & N3-Dy1-N3A & \multicolumn{2}{|c|}{ 71.13(17) } \\
\hline & & & N3-Dy1-O2 & \multicolumn{2}{|c|}{$141.64(12)$} \\
\hline & & & N3-Dy1-O2A & \multicolumn{2}{|c|}{$132.85(12)$} \\
\hline & & & N3-Dy1-O3 & \multicolumn{2}{|c|}{$77.04(12)$} \\
\hline & & & N3-Dy1-O3A & \multicolumn{2}{|c|}{$82.60(12)$} \\
\hline & & & O2-Dy1-N2A & 79 & \\
\hline & & & O2-Dy1--N3A & 13 & 12) \\
\hline & & & O2-Dy1-O3 & 12 & 13) \\
\hline & & & O2-Dy1-O3A & 76 & \\
\hline & & & O2-Dy1-O2A & 51 & \\
\hline & & & O3-Dy1-N2A & 86 & \\
\hline & & & O3-Dy1-N3A & 82 & \\
\hline & & & O3-Dy1-O2A & 76 & \\
\hline & & & O3-Dy1-03A & 15 & 17) \\
\hline Bond & 2 & 3 & Bond angle & 2 & 3 \\
\hline Dy1-N1 & $2.546(5)$ & $2.545(7)$ & N1-Dy1-N2 & $66.05(16)$ & $65.9(2)$ \\
\hline Dy1-N2 & $2.523(4)$ & $2.511(6)$ & N1-Dy1-N3 & $136.17(16)$ & $136.2(2)$ \\
\hline Dy1-N3 & $2.552(4)$ & $2.544(6)$ & N1-Dy1-N4 & $156.89(16)$ & $156.7(2)$ \\
\hline Dy1-N4 & $2.538(5)$ & $2.531(7)$ & N1-Dy1-N5 & $77.58(16)$ & $77.6(2)$ \\
\hline Dy1-N5 & $2.380(5)$ & $2.385(6)$ & N1-Dy1-O1 & $98.67(18)$ & $98.7(2)$ \\
\hline Dy1-01 & $2.156(4)$ & $2.153(5)$ & N1-Dy1-O2 & 89.16(18) & $89.2(3)$ \\
\hline Dy1-O2 & $2.151(4)$ & $2.163(6)$ & N2-Dy1-N3 & 71.86(16) & $72.0(2)$ \\
\hline Dy2-N8 & $2.564(4)$ & $2.564(6)$ & N2-Dy1-N4 & $136.86(16)$ & $137.1(2)$ \\
\hline Dy2-N9 & $2.526(4)$ & $2.520(5)$ & N2-Dy1-N5 & $142.99(17)$ & $143.1(2)$ \\
\hline Dy2-N10 & $2.548(4)$ & $2.545(6)$ & N2-Dy1-O1 & $77.95(15)$ & $77.8(2)$ \\
\hline Dy2-N11 & $2.533(4)$ & $2.520(6)$ & N2-Dy1-O2 & $88.06(16)$ & $88.0(2)$ \\
\hline Dy2-N12 & $2.374(4)$ & $2.391(6)$ & N3-Dy1-N4 & 66.63(15) & $66.9(2)$ \\
\hline Dy2-03 & $2.151(4)$ & $2.148(5)$ & N3-Dy1-N5 & $145.14(16)$ & $144.9(2)$ \\
\hline Dy2-O4 & $2.167(4)$ & $2.171(5)$ & N3-Dy1-O1 & $83.72(15)$ & $83.6(2)$ \\
\hline & & & N3-Dy1-O2 & $77.54(15)$ & $77.5(2)$ \\
\hline & & & N4-Dy1-N5 & 79.32(16) & $79.1(2)$ \\
\hline & & & N4-Dy1-O1 & $86.25(16)$ & $86.0(2)$ \\
\hline & & & N4-Dy1-O2 & $94.00(17)$ & $94.4(3)$ \\
\hline & & & N5-Dy1-01 & $101.91(18)$ & $103.0(2)$ \\
\hline & & & N5-Dy1-O2 & 98.36(18) & $97.5(2)$ \\
\hline
\end{tabular}




\begin{tabular}{llll} 
O1-Dy1-O2 & $159.40(15)$ & $159.2(2)$ \\
N8-Dy2-N9 & $66.66(12)$ & $66.76(18)$ \\
& N8-Dy2-N10 & $136.30(12)$ & $136.68(18)$ \\
N8-Dy2-N11 & $155.82(13)$ & $156.01(19)$ \\
& N8-Dy2-N12 & $77.58(13)$ & $77.39(19)$ \\
& N8-Dy2-O3 & $85.50(13)$ & $85.04(19)$ \\
& N8-Dy2-O4 & $98.46(13)$ & $98.84(19)$ \\
& N9-Dy2-N10 & $71.84(12)$ & $72.06(18)$ \\
& N9-Dy2-N11 & $137.52(13)$ & $137.21(18)$ \\
& N9-Dy2-N12 & $143.95(14)$ & $143.85(18)$ \\
& N9-Dy2-O3 & $84.41(14)$ & $84.42(19)$ \\
& N9-Dy2-O4 & $78.16(13)$ & $78.56(18)$ \\
& N10-Dy2-N11 & $66.80(13)$ & $66.14(18)$ \\
& N10-Dy2-N12 & $143.87(14)$ & $143.82(19)$ \\
& N10-Dy2-O3 & $77.31(13)$ & $78.08(18)$ \\
& N10-Dy2-O4 & $85.71(13)$ & $85.41(17)$ \\
& N11-Dy2-N12 & $78.34(14)$ & $78.77(19)$ \\
& N11-Dy2-O3 & $95.49(13)$ & $95.38(19)$ \\
& N11-Dy2-O4 & $89.35(13)$ & $89.23(18)$ \\
& N12-Dy2-O3 & $97.59(15)$ & $97.4(2)$ \\
& N12-Dy2-O4 & $103.64(15)$ & $103.3(2)$ \\
& O3-Dy2-O4 & $158.76(12)$ & $159.26(18)$ \\
\hline
\end{tabular}

Symmetry code (A): 1-x, $y, 1 / 2-z$. 
Table S2. CShM values calculated by SHAPE $2.1^{1,2}$ for $\mathbf{1}^{\mathrm{a}}, \mathbf{2}^{\mathrm{b}}$ and $\mathbf{3}^{\mathrm{b}}$.

\begin{tabular}{|c|c|c|c|c|c|c|c|}
\hline Metal site & $\begin{array}{l}\text { OP-8 } \\
\left(D_{8 h}\right)\end{array}$ & $\begin{array}{l}\text { HPY-8 } \\
\left(C_{7 v}\right)\end{array}$ & $\begin{array}{l}\text { HBPY-8 } \\
\left(D_{6 h}\right)\end{array}$ & $\begin{array}{l}\mathrm{CU}-8 \\
\left(O_{h}\right)\end{array}$ & $\begin{array}{l}\text { SAPR-8 } \\
\left(D_{4 d}\right)\end{array}$ & $\begin{array}{l}\text { TDD-8 } \\
\left(D_{2 d}\right)\end{array}$ & $\begin{array}{l}\text { JGBF-8 } \\
\left(D_{2 d}\right)\end{array}$ \\
\hline \multirow{3}{*}{$1_{\mathrm{Dy} 1}$} & 30.353 & 22.544 & 12.228 & 10.187 & 3.519 & 2.697 & 10.039 \\
\hline & $\begin{array}{l}\text { JETBPY-8 } \\
\left(D_{3 h}\right)\end{array}$ & $\begin{array}{l}\text { JBTP-8 } \\
\left(C_{2 v}\right)\end{array}$ & $\begin{array}{l}\text { BTPR-8 } \\
\left(C_{2 v}\right)\end{array}$ & $\begin{array}{l}\text { JSD-8 } \\
\left(D_{2 d}\right)\end{array}$ & $\begin{array}{l}\text { TT-8 } \\
\left(T_{d}\right)\end{array}$ & $\begin{array}{l}\text { ETBPY-8 } \\
\left(D_{3 h}\right)\end{array}$ & \\
\hline & 26.668 & 3.426 & 3.169 & 3.006 & 11.031 & 23.950 & \\
\hline Metal site & $\begin{array}{l}\text { HP-7 } \\
\left(D_{7 h}\right)\end{array}$ & $\begin{array}{l}\text { HPY-7 } \\
\left(C_{6 v}\right)\end{array}$ & $\begin{array}{l}\text { PBPY-7 } \\
\left(D_{5 h}\right)\end{array}$ & $\begin{array}{l}\text { COC-7 } \\
\left(C_{3 v}\right)\end{array}$ & $\begin{array}{l}\text { CTPR-7 } \\
\left(C_{2 v}\right)\end{array}$ & $\begin{array}{l}\text { JPBPY-7 } \\
\left(D_{5 h}\right)\end{array}$ & $\begin{array}{l}\text { JETPY-7 } \\
\left(C_{3 v}\right)\end{array}$ \\
\hline $2_{\text {Dy1 }}$ & 32.615 & 22.470 & 1.355 & 7.471 & 5.746 & 2.272 & 19.972 \\
\hline $2_{\text {Dy2 }}$ & 32.864 & 22.394 & 1.364 & 7.753 & 6.199 & 2.294 & 19.735 \\
\hline $3_{\text {Dy1 }}$ & 32.497 & 22.266 & 1.373 & 7.613 & 5.820 & 2.343 & 19.805 \\
\hline $3_{\text {Dy2 }}$ & 32.771 & 22.434 & 1.341 & 7.868 & 6.199 & 2.289 & 19.787 \\
\hline
\end{tabular}

aOP-8 = Octagon, HPY-8 = Heptagonal pyramid, HBPY-8 = Hexagonal bipyramid, CU-8 = Cube, SAPR-8 = Square antiprism, TDD-8 = Triangular dodecahedron, JGBF-8 = Johnson - Gyrobifastigium J26, JETBPY-8 = Johnson - Elongated triangular bipyramid J14, JBTP-8 = Johnson - Biaugmented trigonal prism J50, BTPR-8 = Biaugmented trigonal prism, JSD-8 $=$ Snub disphenoid J84, TT-8 $=$ Triakis tetrahedron, ETBPY-8 = Elongated trigonal bipyramid J14.

bHP-7 = Heptagon, HPY-7 = Hexagonal pyramid, PBPY-7 = Pentagonal bipyramid, COC-7 = Capped octahedron, CTPR-7 = Capped trigonal prism, JPBPY-7 = Johnson pentagonal bipyramid J13, JETPY-7 = Johnson elongated triangular pyramid J7.

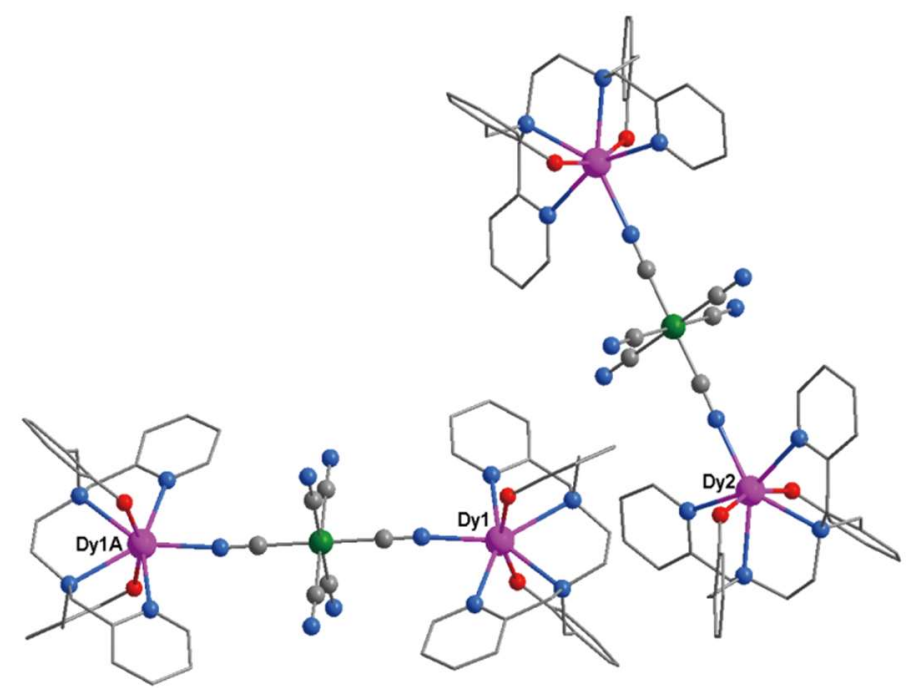

Figure S3. Two [Dy2 $\left.(\text { bbpen })_{2}\left\{\mathrm{Fe}(\mathrm{CN})_{6}\right\}\right]^{-}$units adjacent to each other in a unit cell. Color codes: Dy, pink; Fe, green; N, blue; O, red; C, gray. Hydrogen atoms are omitted for clarity. 


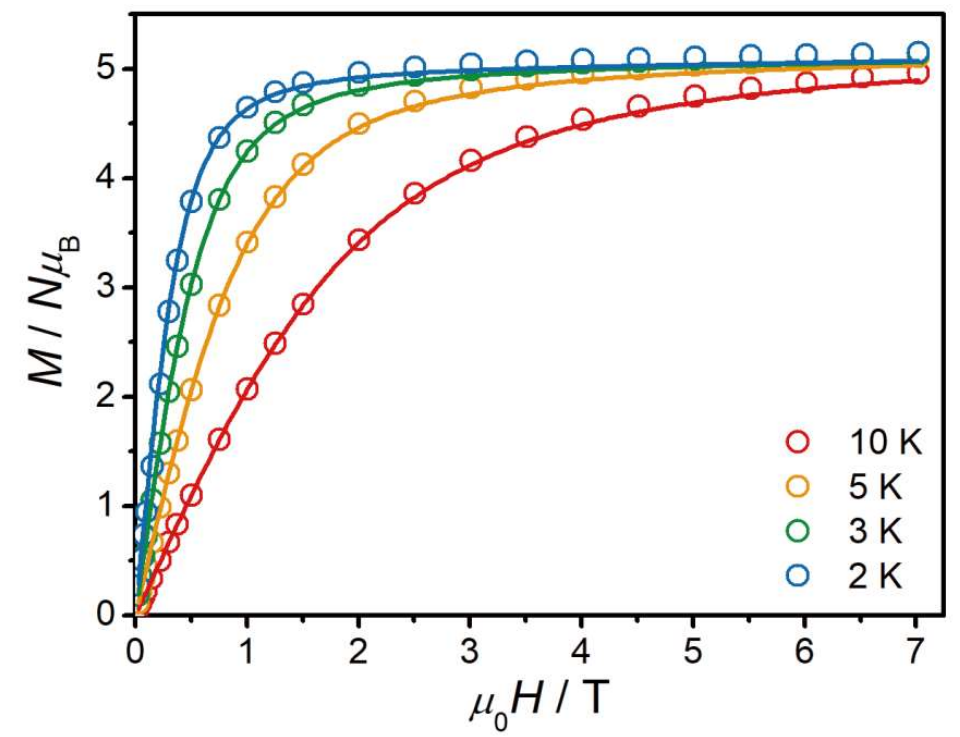

Figure S4. Variable-field magnetization data for 1. Data were collected from 0-7 T in steady fields. The solid lines correspond to the ab initio calculations.
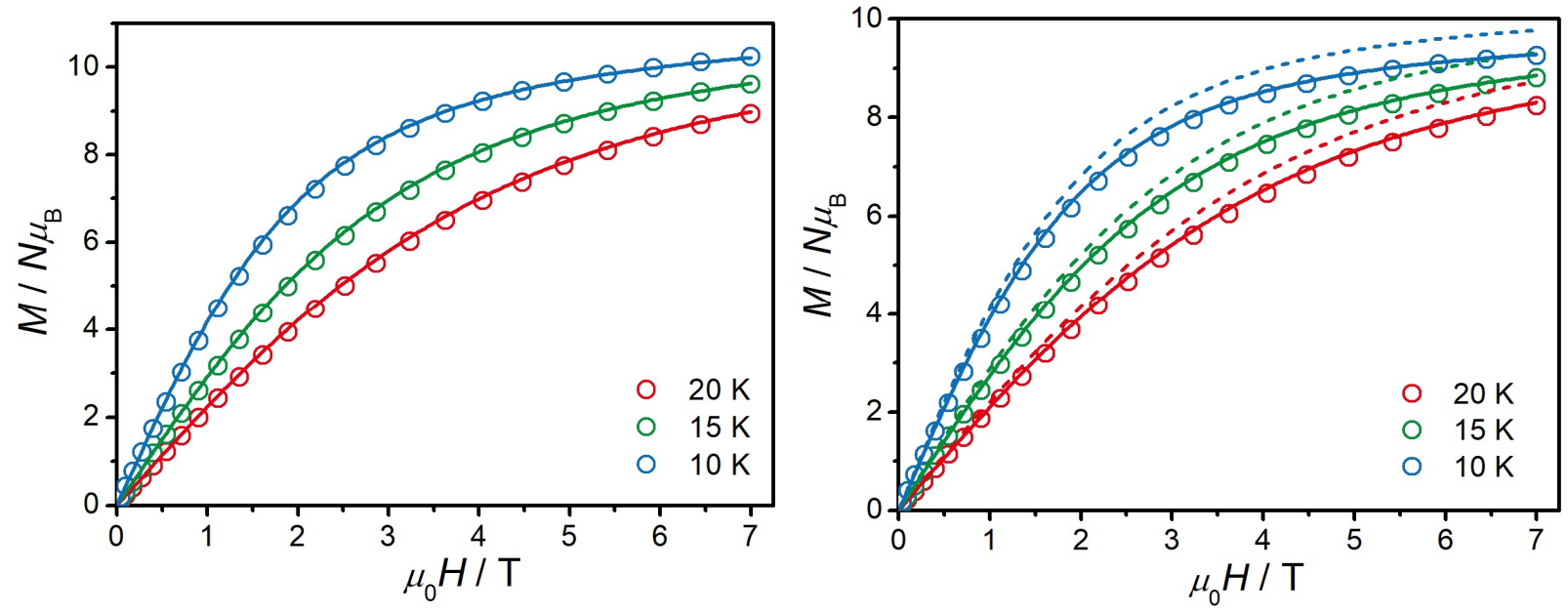

Figure S5. Variable-field magnetization data for 2 (left) and 3 (right). Data were collected from 0-7 T in steady fields. The solid lines correspond to the ab initio calculations. The calculated lines for complex 3 are scaled down by $0.95^{3,4}$ (original: dashed lines; scaled: solid lines). 


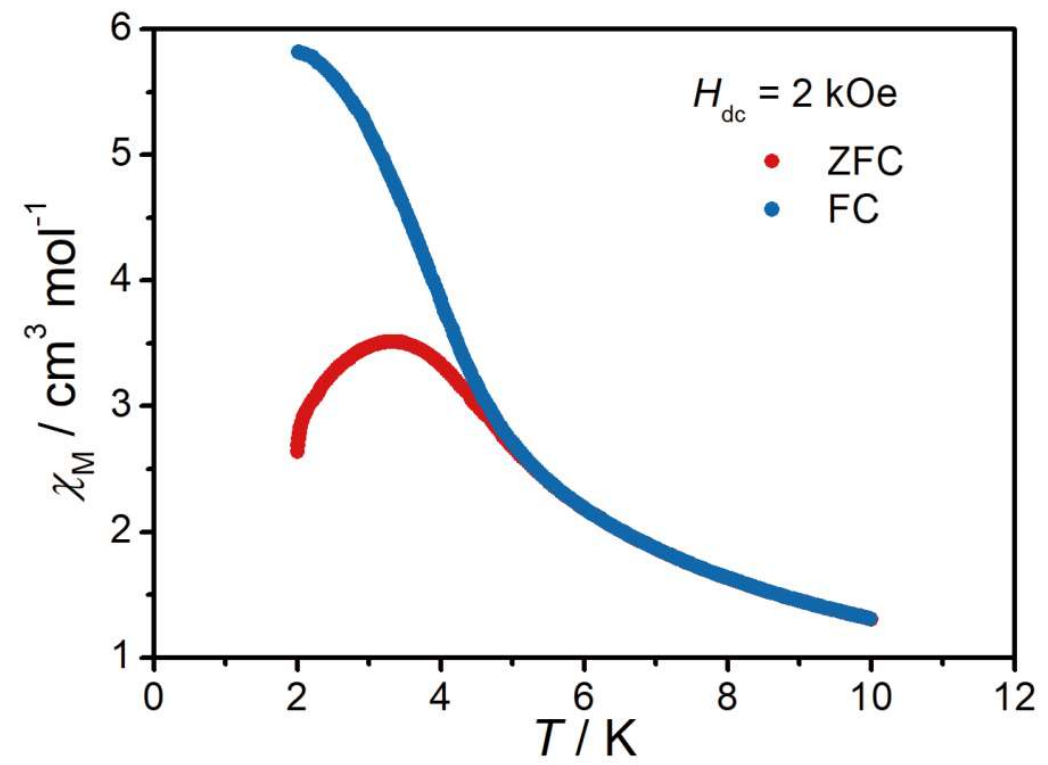

Figure S6. The zero-field-cooled/field-cooled (ZFC/FC) magnetic susceptibilities were measured under a 2 kOe dc field (sweep rate $2 \mathrm{~K} \mathrm{~min}^{-1}$ ), with divergences at $5.0 \mathrm{~K}$ for 1 , which takes from the normalized difference of ZFC-FC magnetization of $1 \%$ as a cut-off criterion. ${ }^{5}$
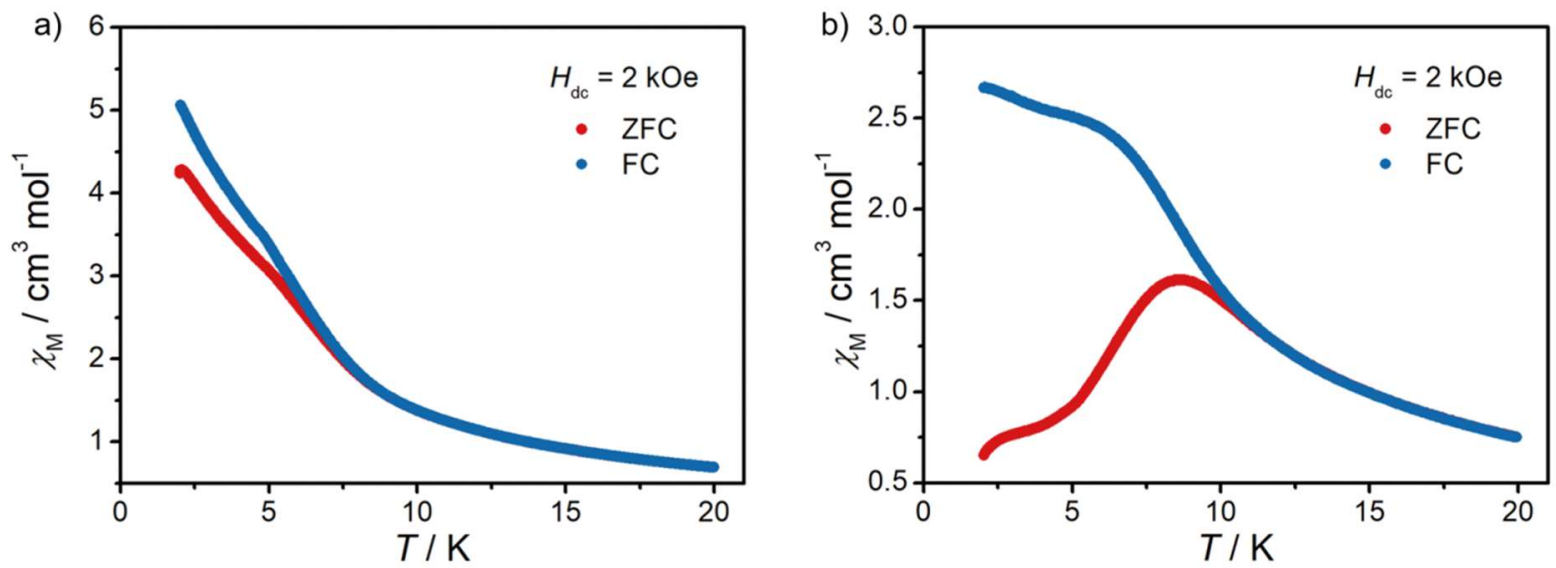

Figure S7. The zero-field-cooled/field-cooled (ZFC/FC) magnetic susceptibilities were measured under a 2 kOe dc field (sweep rate $2 \mathrm{~K} \mathrm{~min}^{-1}$ ), with divergences at $8.0 \mathrm{~K}$ for 2 and $10.8 \mathrm{~K}$ for 3 , which takes the normalized difference of ZFC-FC magnetization of $1 \%$ as a cut-off criterion. ${ }^{5}$ 

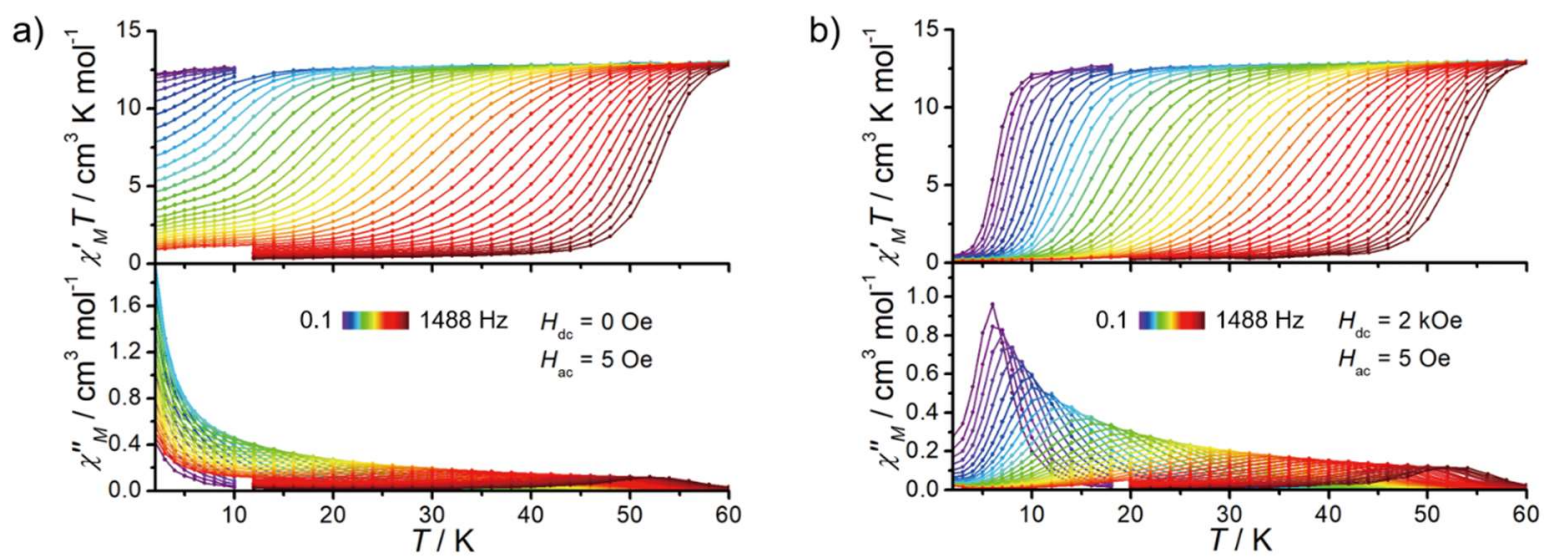

Figure S8. Temperature dependence of the in-phase $\chi \mathrm{m}^{\prime} T$ product and out-of-phase $\chi \mathrm{m}^{\prime \prime}$ for 1 (a) under a zero dc field, (b) under $2 \mathrm{kOe}$ dc field. The solid lines are guides for the eyes.

a)

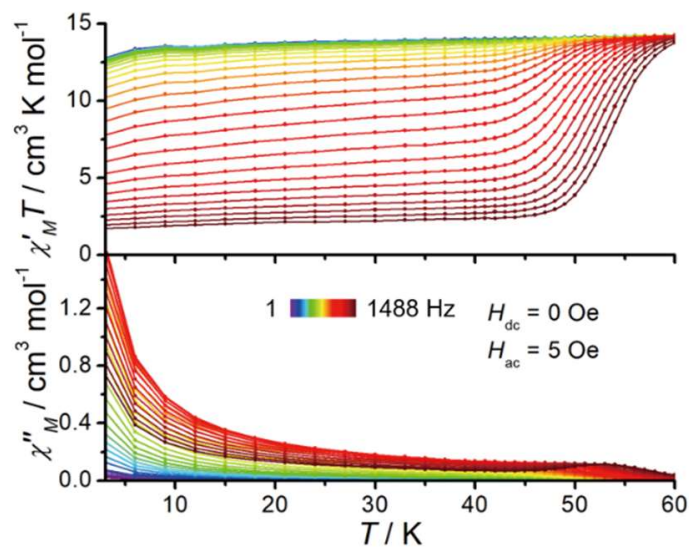

b)

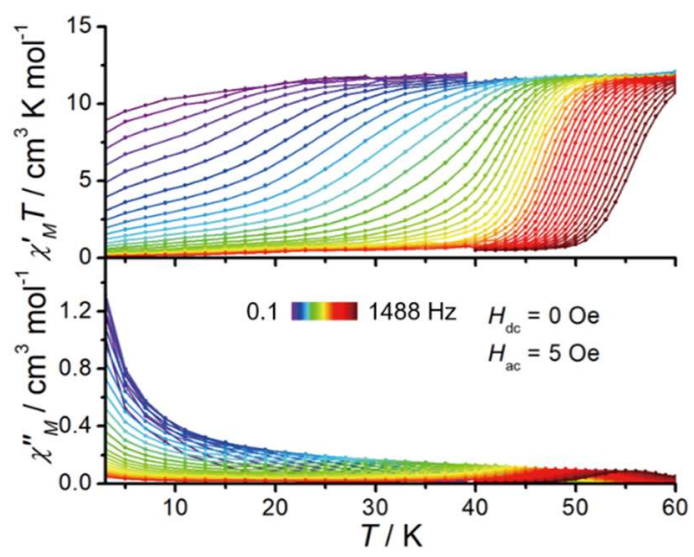

Figure S9. Temperature dependence of the in-phase $\chi \mathrm{M}^{\prime} T$ product and out-of-phase $\chi \mathrm{m}^{\prime \prime}$ for $\mathbf{2}(\mathrm{a})$ and $\mathbf{3}$ (b) under 0 Oe dc field. The solid lines are guides for the eyes.
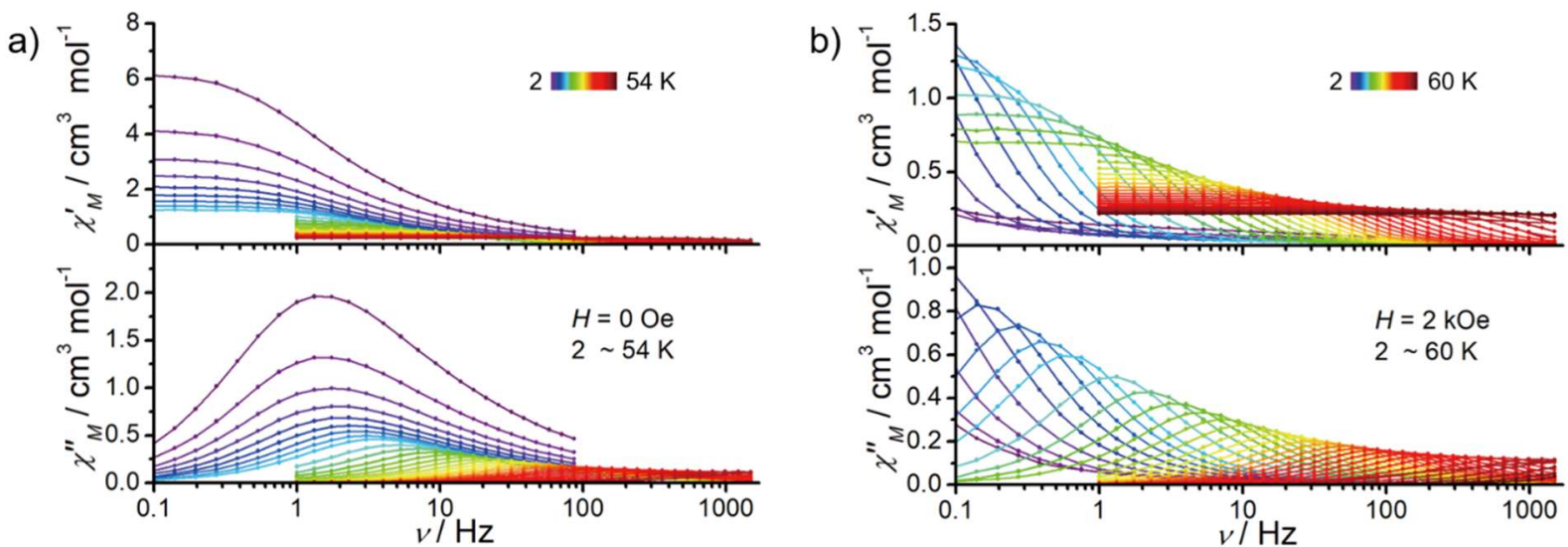

Figure S10. Frequency dependence of ac magnetic susceptibilities at variable temperatures for $\mathbf{1}$ (a) under a zero dc field, (b) under $2 \mathrm{kOe}$ dc field. The solid lines are guides for the eyes. 

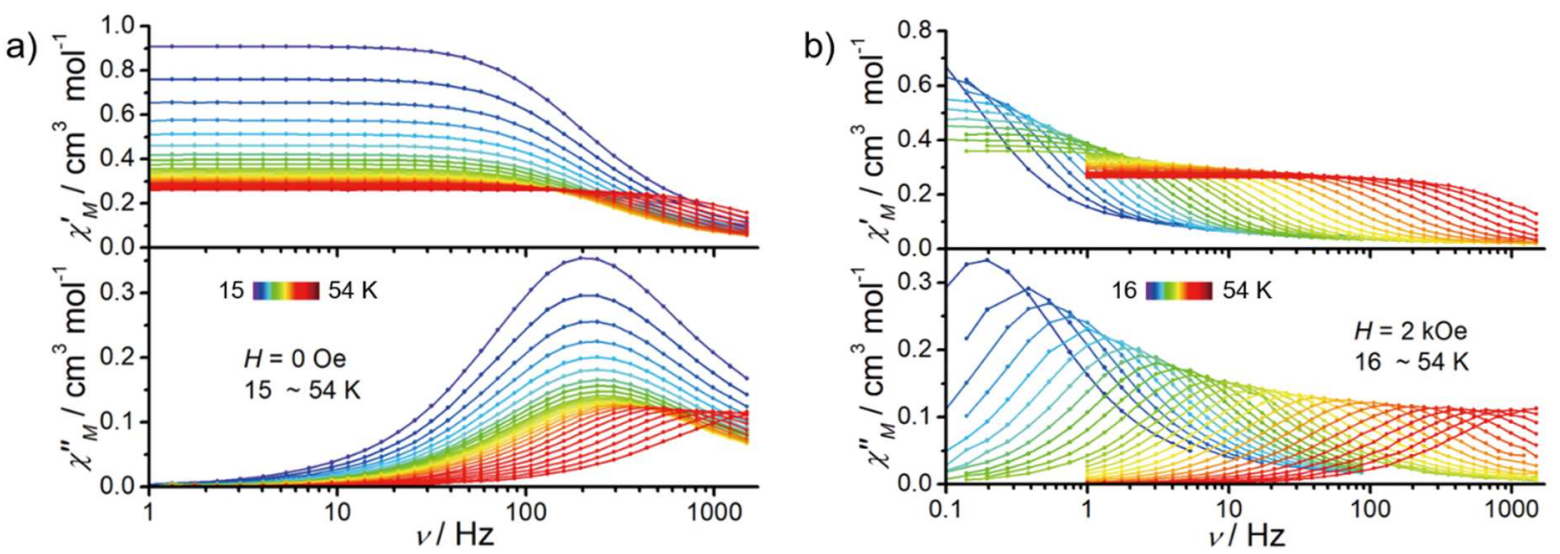

Figure S11. Frequency dependence of ac magnetic susceptibilities at variable temperatures for 2 (a) under a zero dc field, (b) under $2 \mathrm{kOe} d c$ field. The solid lines are guides for the eyes.
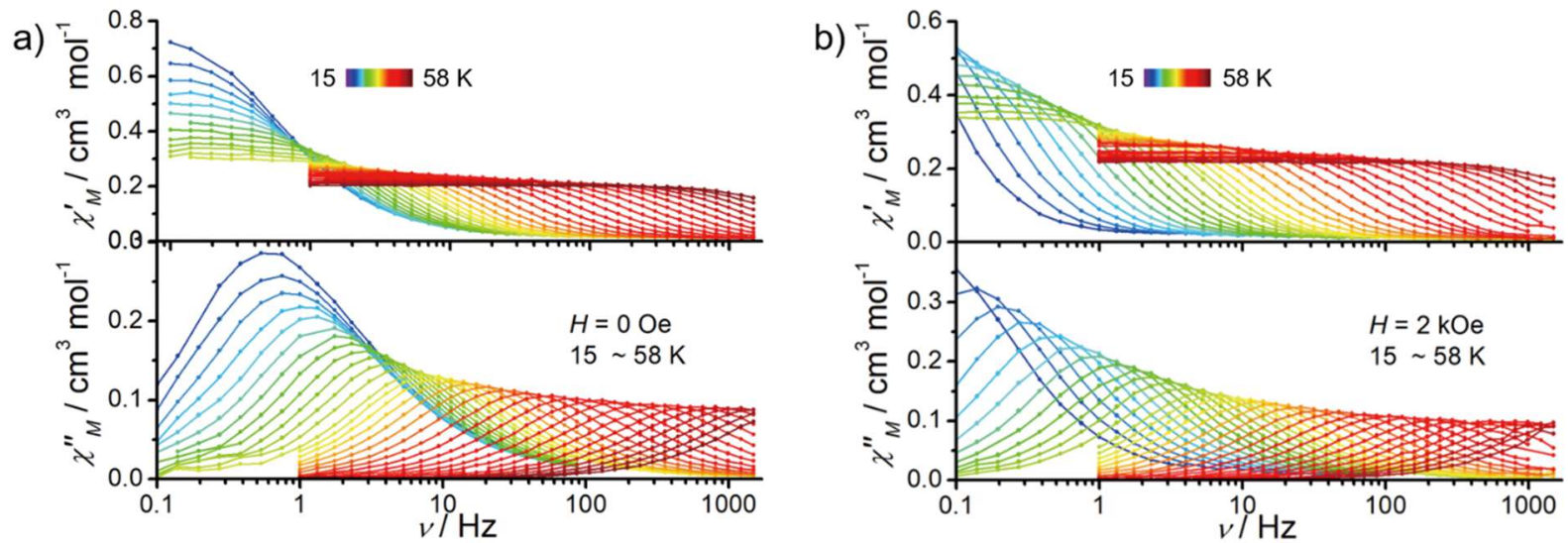

Figure S12. Frequency dependence of ac magnetic susceptibilities at variable temperatures for $\mathbf{3}$ (a) under a zero dc field, (b) under $2 \mathrm{kOe} d c$ field. The solid lines are guides for the eyes.
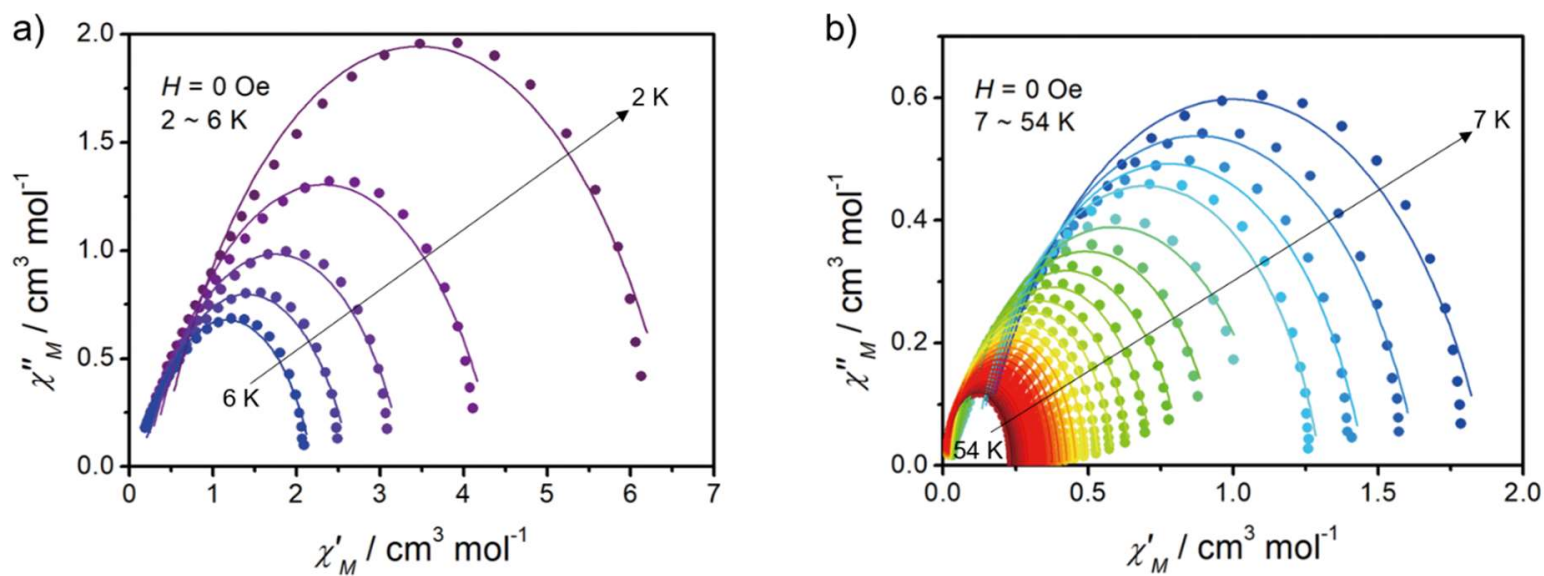

Figure S13. Cole-Cole plots for the ac susceptibilities for 1 under a zero dc field ( $\alpha=0.0094-0.29)$. The solid lines are best fit for the generalized Debye model. 


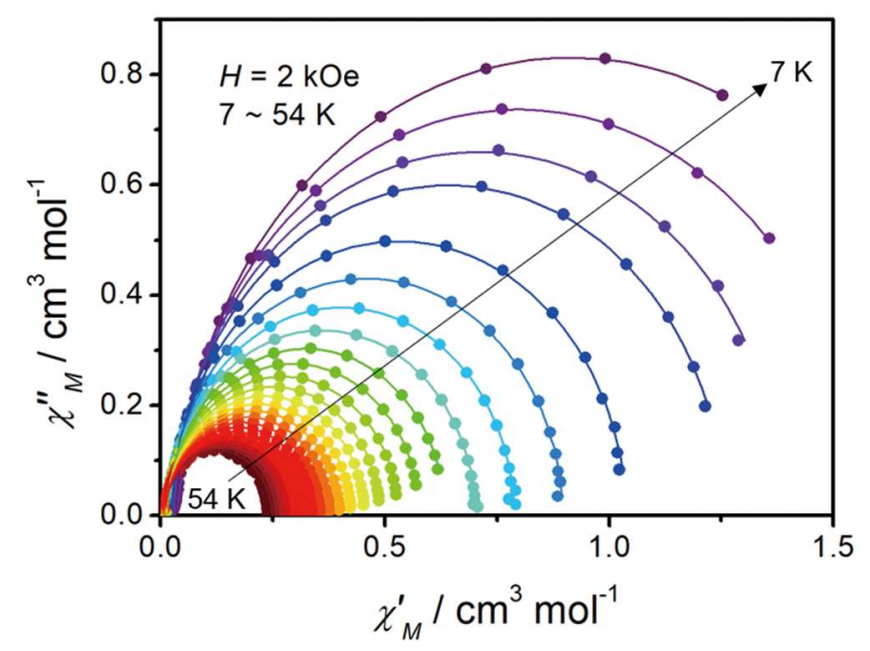

Figure S14. Cole-Cole plots for the ac susceptibilities for 1 under $2 \mathrm{kOe}$ dc field ( $\alpha=0.0097-0.41)$. The solid lines are best fit for the generalized Debye model.
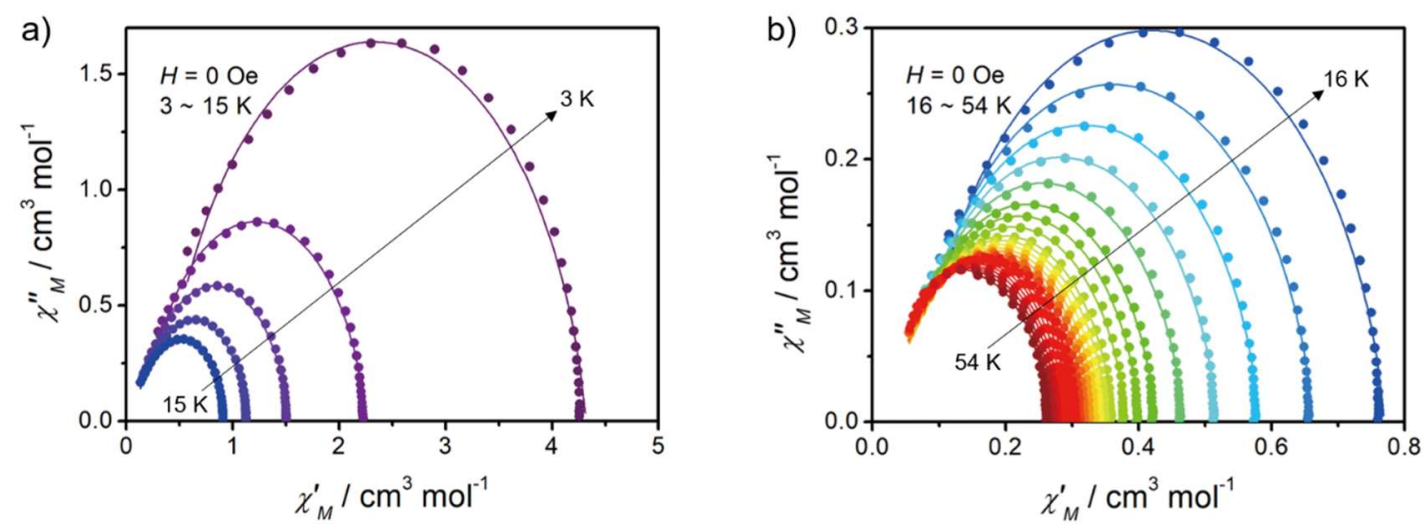

Figure S15. Cole-Cole plots for the ac susceptibilities for 2 under a zero dc field ( $\alpha=0.039-0.12)$. The solid lines are best fit for the generalized Debye model.

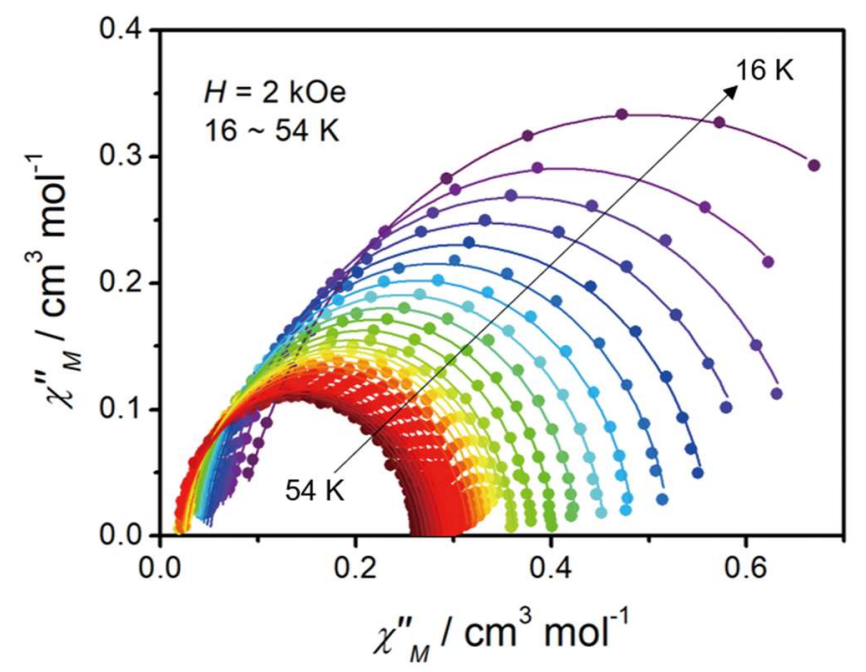

Figure S16. Cole-Cole plots for the ac susceptibilities for 2 under $2 \mathrm{kOe}$ dc field $(\alpha=0.046-0.14)$. The solid lines are best fit for the generalized Debye model. 

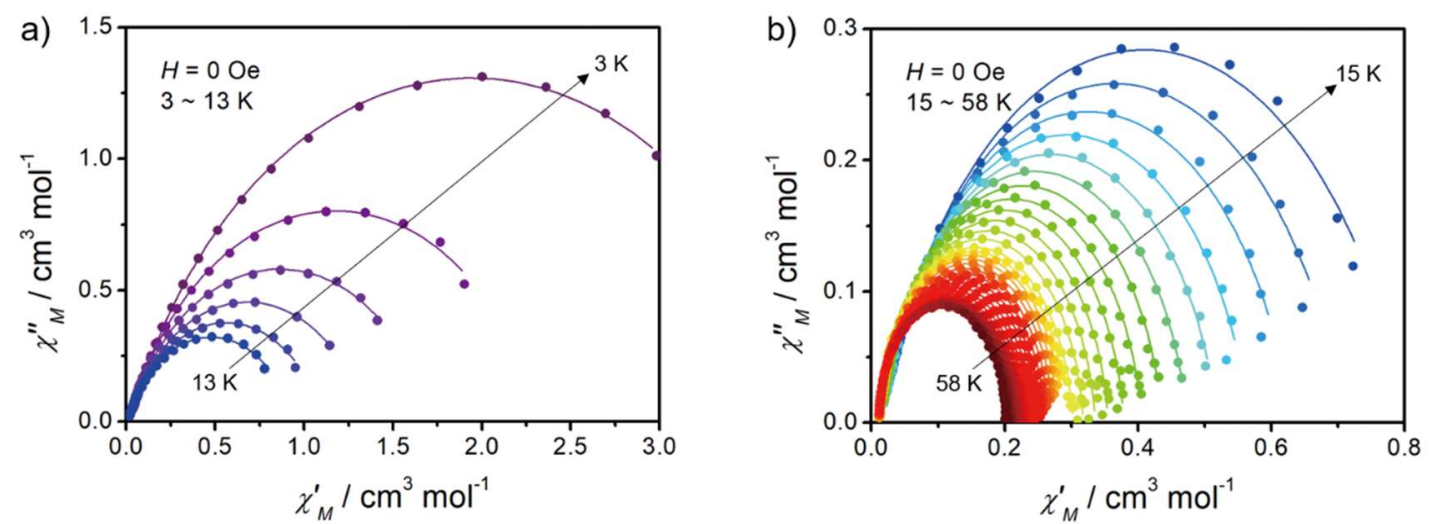

Figure S17. Cole-Cole plots for the ac susceptibilities for 3 under a zero dc field ( $\alpha=0.045-0.24)$. The solid lines are best fit for the generalized Debye model.

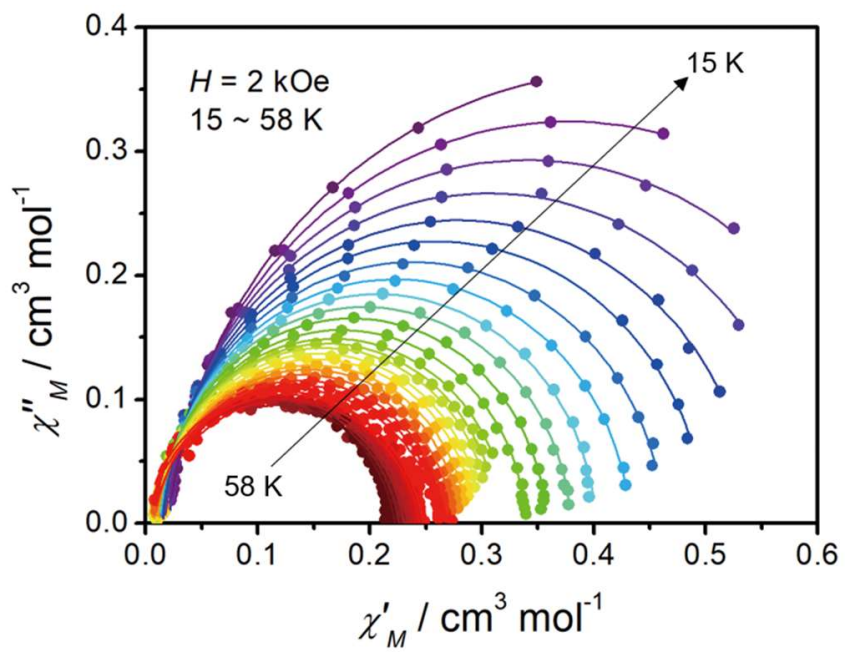

Figure S18. Cole-Cole plots for the ac susceptibilities for 3 under $2 \mathrm{kOe}$ dc field ( $\alpha=0.029-0.12$ ). The solid lines are best fit for the generalized Debye model.

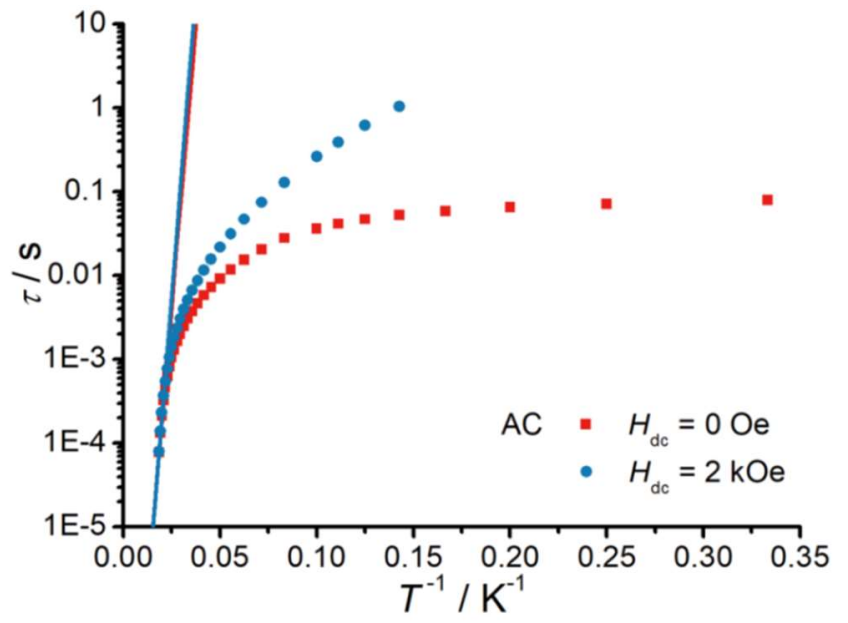

Figure S19. Temperature dependence of the magnetic relaxation time $\tau$ under $0 \mathrm{Oe}$ (red) and $2 \mathrm{kOe}$ (blue) is shown as $\tau$ versus $T^{-1}$ for 1 . The solid lines correspond to the Arrhenius law fitting at high temperatures. 

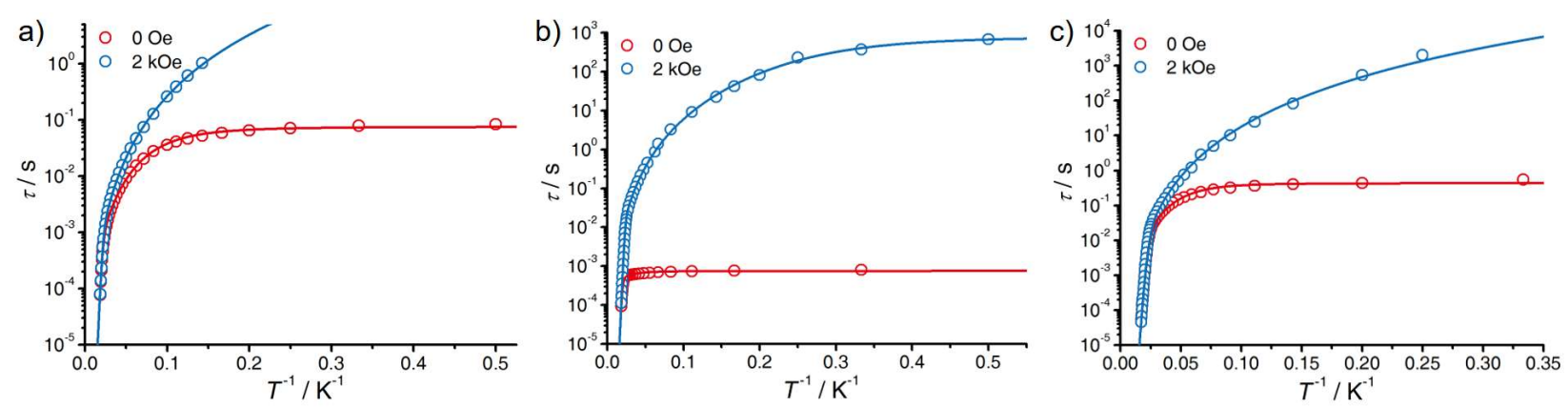

Figure S20. Temperature dependence of the magnetic relaxation time $\tau$ under $0 \mathrm{Oe}$ (red) and $2 \mathrm{kOe}$ (blue) is shown as $\tau$ versus $T^{-1}$ for $\mathbf{1}$ (a), 2 (b) and $\mathbf{3}$ (c). The solid lines correspond to the fitting of $\tau^{-1}=$ $\tau_{0}{ }^{-1} \exp \left(-U_{\text {efff }} / k_{\mathrm{B}} T\right)+C T^{n}+\tau_{Q T M^{-1}}$, sharing $\tau_{0}$ and $U_{\text {eff }} / k_{\mathrm{B}}$ parameters for zero-field and applied field data. The best fits are as follows: $1(0 \mathrm{Oe}): \tau_{0}=1.5(7) \times 10^{-10} \mathrm{~s}, U_{\text {eff }} / \mathrm{k}_{\mathrm{B}}=725(23) \mathrm{K}, C=0.015(2) \mathrm{s}^{-1} \mathrm{~K}^{-n}, n=2.94(4)$, $\tau_{Q T M}=0.075(2) \mathrm{s} ; 1(2 \mathrm{kOe}): \tau 0=1.5(7) \times 10^{-10} \mathrm{~s}, U_{\text {eff }} / \mathrm{kB}_{\mathrm{B}}=725(23) \mathrm{K}, C=8.8(6) \times 10^{-4} \mathrm{~s}^{-1} \mathrm{~K}^{-n}, n=3.63(2)$, no $\tau_{Q T M} ; 2(0 \mathrm{Oe}): \tau_{0}=1.0(3) \times 10^{-12} \mathrm{~s}, U_{\text {eff }} / \mathrm{kB}_{\mathrm{B}}=1002(14) \mathrm{K}, C=0.2(5) \mathrm{s}^{-1} \mathrm{~K}^{-n}, n=2.1(5), \tau_{Q T M}=7.5(3) \times 10^{-4}$ $\mathrm{s} ; 2(2 \mathrm{kOe}): \tau_{0}=1.0(3) \times 10^{-12} \mathrm{~s}, U_{\text {eff }} / \mathrm{k}_{\mathrm{B}}=1002(14) \mathrm{K}, C=1.39(9) \times 10^{-5} \mathrm{~s}^{-1} \mathrm{~K}^{-n}, n=4.07(2), \tau_{Q T M}=782(49)$ $\mathrm{s} ; 3(0 \mathrm{Oe}): \tau_{0}=5.7(17) \times 10^{-13} \mathrm{~s}, U_{\text {eff }} / \mathrm{k}_{\mathrm{B}}=1065(16) \mathrm{K}, C=1.2(6) \times 10^{-4} \mathrm{~s}^{-1} \mathrm{~K}^{-n}, n=3.46(13), \tau_{\text {QTM }}=0.43(2)$; $3(2 \mathrm{kOe}): \tau_{0}=5.7(17) \times 10^{-13} \mathrm{~s}, U_{\text {eff }} / k_{\mathrm{B}}=1065(16) \mathrm{K}, C=1.06(10) \times 10^{-6} \mathrm{~s}^{-1} \mathrm{~K}^{-n}, n=4.72(3)$, no $\tau_{Q T M}$.
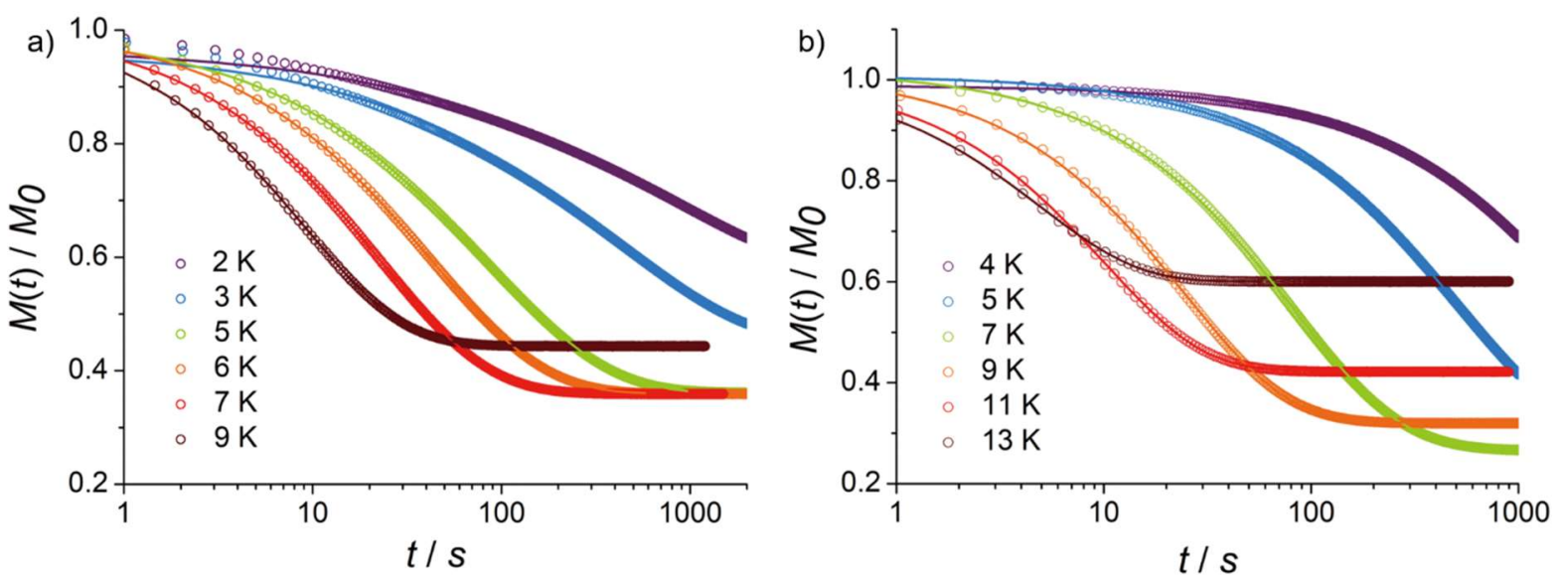

Figure S21. DC magnetization decay of 2 (a) and $\mathbf{3}$ (b) with final field of $2 \mathrm{kOe}$. The magnetic field was ramped to $3 \mathrm{~T}$ and the temperature was declined to the indicated temperature. After temperature and magnetic moment are steady, the magnetic field was started to reach $0.2 \mathrm{~T}$, and kept unchanged for at least $10^{3} \sim 10^{4} \mathrm{~s}$ depending on the measured temperature. During the procedure, the magnetization kept measuring. The solid lines are the best fit to the exponential decay as $M(t)=M_{f}+\left(M_{i}-M_{f}\right) \exp \left[-(t / \tau)^{\beta}\right]$, where $\tau$ is the relaxation time. 
Table S3. The fitting parameters of dc magnetization decay derived from $M(t)=M_{f}+\left(M_{i}-M_{f}\right) \exp \left[-(t / \tau)^{\beta}\right]$ for 2 and 3 with final field of $2 \mathrm{kOe}$.

\begin{tabular}{|c|c|c|c|c|c|c|c|c|c|}
\hline & $T(\mathrm{~K})$ & $\begin{array}{c}M_{f} \\
(\mathrm{emu})\end{array}$ & $\begin{array}{l}\text { Error } \\
\text { (emu) }\end{array}$ & $\begin{array}{c}M_{i} \\
\text { (emu) }\end{array}$ & $\begin{array}{l}\text { Error } \\
\text { (emu) }\end{array}$ & $\tau(\mathbf{s})$ & $\begin{array}{c}\text { Error } \\
\text { (s) }\end{array}$ & $\beta$ & Error \\
\hline \multirow{6}{*}{2} & 2 & 0.16675 & $5.87945 \times 10^{-5}$ & 0.28627 & $1.50016 \times 10^{-4}$ & 674.64732 & 1.46893 & 0.51122 & $1.1 \times 10^{-3}$ \\
\hline & 3 & 0.11916 & $3.28934 \times 10^{-5}$ & 0.25806 & $1.48075 \times 10^{-4}$ & 369.48503 & 0.71371 & 0.56594 & $9.1 \times 10^{-4}$ \\
\hline & 5 & 0.0753 & $9.69597 \times 10^{-6}$ & 0.20848 & $6.03555 \times 10^{-5}$ & 81.44339 & 0.06588 & 0.65235 & $4.3 \times 10^{-4}$ \\
\hline & 6 & 0.06359 & $4.79313 \times 10^{-6}$ & 0.17792 & $3.88148 \times 10^{-5}$ & 41.92831 & 0.02511 & 0.71108 & $3.5 \times 10^{-4}$ \\
\hline & 7 & 0.05487 & $4.46383 \times 10^{-6}$ & 0.15381 & $3.93456 \times 10^{-5}$ & 22.35216 & 0.01533 & 0.73855 & $4.3 \times 10^{-4}$ \\
\hline & 9 & 0.04307 & $8.25489 \times 10^{-6}$ & 0.09786 & $6.69918 \times 10^{-5}$ & 9.16739 & 0.01855 & 0.82434 & $1.6 \times 10^{-3}$ \\
\hline \multirow{6}{*}{3} & 4 & 0.13568 & $3.25076 \times 10^{-5}$ & 0.44282 & $2.09747 \times 10^{-5}$ & 2020.55101 & 0.43842 & 0.77829 & $1.6 \times 10^{-4}$ \\
\hline & 5 & 0.10825 & $1.92627 \times 10^{-5}$ & 0.39902 & $7.01113 \times 10^{-5}$ & 536.63526 & 0.19365 & 0.78766 & $3.4 \times 10^{-4}$ \\
\hline & 7 & 0.07765 & $2.39543 \times 10^{-5}$ & 0.29492 & $1.81101 \times 10^{-4}$ & 82.7767 & 0.10956 & 0.82537 & $1.1 \times 10^{-3}$ \\
\hline & 9 & 0.06055 & $2.05554 \times 10^{-5}$ & 0.19108 & $1.75812 \times 10^{-4}$ & 24.62453 & 0.05304 & 0.86489 & $1.9 \times 10^{-3}$ \\
\hline & 11 & 0.04983 & $2.74647 \times 10^{-5}$ & 0.11818 & $1.24169 \times 10^{-4}$ & 10.07357 & 0.02965 & 0.90353 & $3.1 \times 10^{-3}$ \\
\hline & 13 & 0.04204 & $1.01872 \times 10^{-5}$ & 0.07007 & $5.29126 \times 10^{-5}$ & 4.953394 & 0.01631 & 0.91975 & $3.5 \times 10^{-3}$ \\
\hline
\end{tabular}

a)

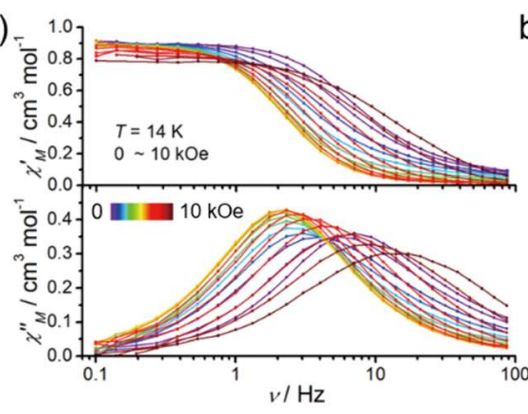

b)

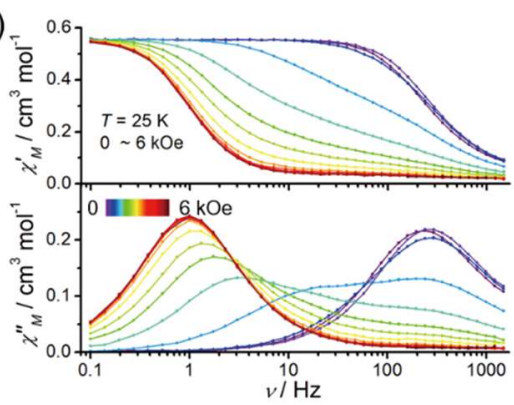

c)

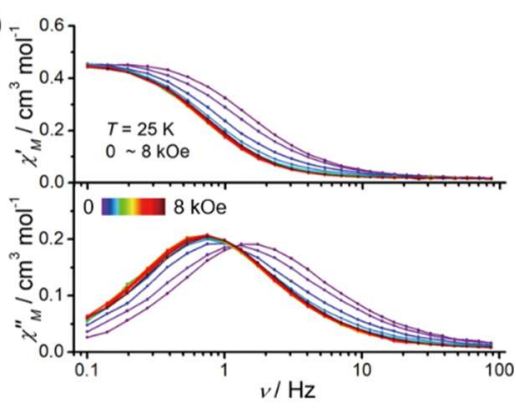

Figure S22. Field dependences of ac magnetic susceptibilities at variable temperatures for $\mathbf{1}$ (a), 2 (b) and $\mathbf{3}$ (c). The solid lines are guides for the eyes.

a)

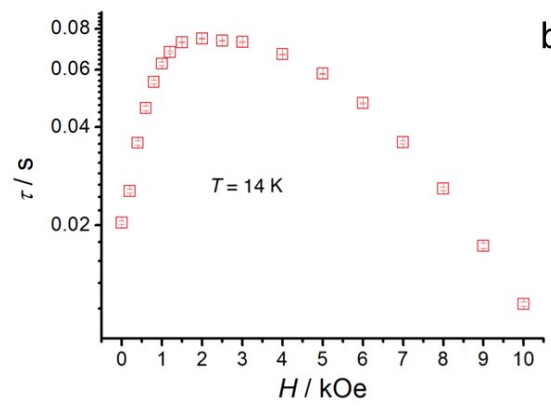

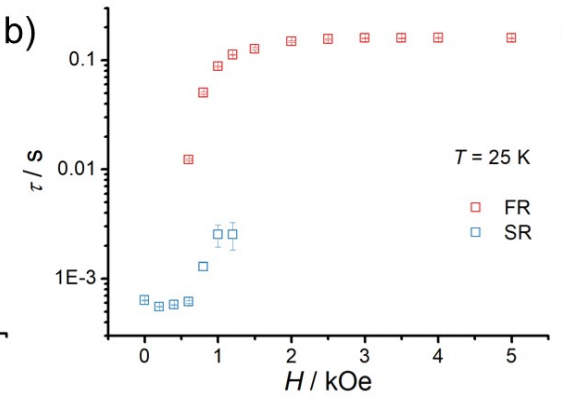

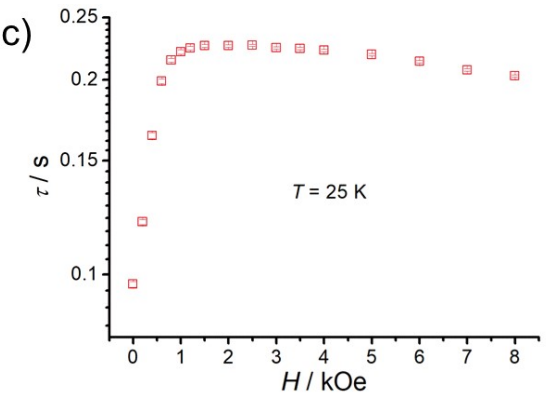

Figure S23. Field dependences of magnetic relaxation times $(\tau)$ for $\mathbf{1}$ (a), 2 (b) and $\mathbf{3}$ (c). 


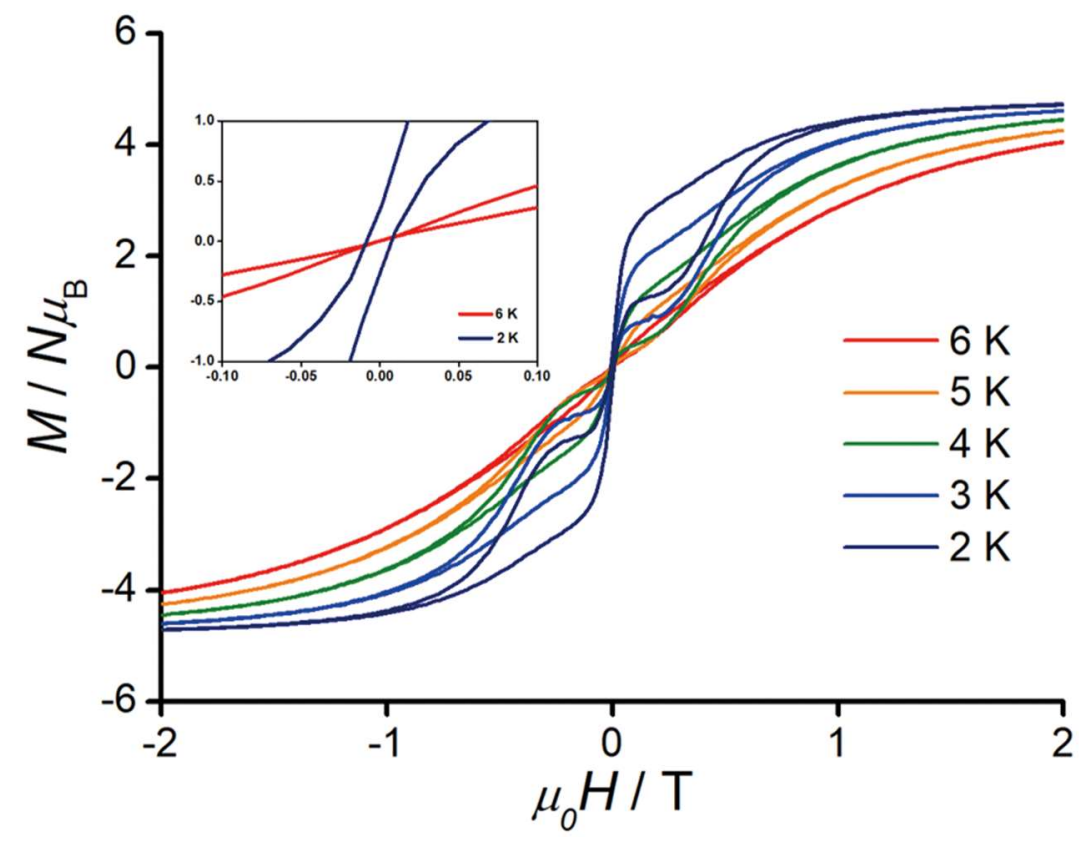

Figure S24. Magnetic hysteresis loops at a field sweep rate of $0.02 \mathrm{~T} / \mathrm{s}$ at the indicated temperatures for 1 . 
Table S4. Energy barriers and pre-exponential factor derived from the Arrhenius expression for 1, 2 and $\mathbf{3}$ under 0 Oe dc field.

\begin{tabular}{|c|c|c|c|c|c|}
\hline Compound & Fitting temperature & $U_{\text {eff }} / k_{\mathrm{B}}(\mathrm{K})$ & Error (K) & $\tau_{0}(\mathbf{s})$ & Error (s) \\
\hline \multirow{3}{*}{1} & $50-54 \mathrm{~K}(2 \mathrm{~K}$ interval $)$ & 683 & 40 & $2.54 \times 10^{-10}$ & $1.96 \times 10^{-10}$ \\
\hline & $48-54 \mathrm{~K}(2 \mathrm{~K}$ interval $)$ & 617 & 39 & $8.84 \times 10^{-10}$ & $6.86 \times 10^{-10}$ \\
\hline & $46-54 \mathrm{~K}(2 \mathrm{~K}$ interval $)$ & 554 & 40 & $2.97 \times 10^{-9}$ & $2.39 \times 10^{-9}$ \\
\hline \multirow{3}{*}{2} & $52-54 \mathrm{~K}(1 \mathrm{~K}$ interval $)$ & 677 & 3 & $3.36 \times 10^{-10}$ & $2.04 \times 10^{-11}$ \\
\hline & $51-54 \mathrm{~K}(1 \mathrm{~K}$ interval $)$ & 659 & 10 & $4.67 \times 10^{-10}$ & $8.86 \times 10^{-11}$ \\
\hline & $50-54 \mathrm{~K}(1 \mathrm{~K}$ interval $)$ & 628 & 18 & $8.42 \times 10^{-10}$ & $2.96 \times 10^{-10}$ \\
\hline \multirow{3}{*}{3} & $47-58 \mathrm{~K}(1 \mathrm{~K}$ interval $)$ & 989 & 7 & $2.18 \times 10^{-12}$ & $3.04 \times 10^{-13}$ \\
\hline & $46-58 \mathrm{~K}(1 \mathrm{~K}$ interval $)$ & 974 & 10 & $2.88 \times 10^{-12}$ & $5.56 \times 10^{-13}$ \\
\hline & $45-58 \mathrm{~K}(1 \mathrm{~K}$ interval $)$ & 955 & 13 & $4.13 \times 10^{-12}$ & $1.06 \times 10^{-12}$ \\
\hline
\end{tabular}

Table S5. Energy barriers and pre-exponential factor derived from the Arrhenius expression for 1, 2 and $\mathbf{3}$ under $2 \mathrm{kOe}$ dc field.

\begin{tabular}{rlrrrr}
\hline Compound & Fitting temperature & $\boldsymbol{U}_{\text {eff }} / \boldsymbol{k}_{\mathrm{B}}(\mathrm{K})$ & Error $(\mathrm{K})$ & $\tau_{0}(\mathbf{s})$ & Error $(\mathbf{s})$ \\
\hline \multirow{3}{*}{$\mathbf{1}$} & $50-54 \mathrm{~K}(2 \mathrm{~K}$ interval $)$ & 723 & 37 & $1.24 \times 10^{-10}$ & $8.94 \times 10^{-11}$ \\
\cline { 2 - 6 } & $48-54 \mathrm{~K}(2 \mathrm{~K}$ interval $)$ & 661 & 37 & $4.00 \times 10^{-10}$ & $2.91 \times 10^{-10}$ \\
\cline { 2 - 6 } & $46-54 \mathrm{~K}(2 \mathrm{~K}$ interval $)$ & 598 & 39 & $1.36 \times 10^{-9}$ & $1.08 \times 10^{-9}$ \\
\hline \multirow{3}{*}{$\mathbf{2}$} & $48-54 \mathrm{~K}(1 \mathrm{~K}$ interval $)$ & 1000 & 13 & $1.07 \times 10^{-12}$ & $2.84 \times 10^{-13}$ \\
\cline { 2 - 6 } & $47-54 \mathrm{~K}(1 \mathrm{~K}$ interval $)$ & 982 & 14 & $1.49 \times 10^{-12}$ & $4.03 \times 10^{-13}$ \\
\cline { 2 - 6 } & $46-54 \mathrm{~K}(1 \mathrm{~K}$ interval $)$ & 962 & 15 & $2.22 \times 10^{-12}$ & $6.74 \times 10^{-13}$ \\
\hline \multirow{3}{*}{3} & $50-58 \mathrm{~K}(1 \mathrm{~K}$ interval $)$ & 1088 & 26 & $3.58 \times 10^{-13}$ & $1.74 \times 10^{-13}$ \\
\cline { 2 - 6 } & $49-58 \mathrm{~K}(1 \mathrm{~K}$ interval $)$ & 1076 & 22 & $4.51 \times 10^{-13}$ & $1.82 \times 10^{-13}$ \\
\cline { 2 - 6 } & $48-58 \mathrm{~K}(1 \mathrm{~K}$ interval $)$ & 1054 & 21 & $6.69 \times 10^{-13}$ & $2.64 \times 10^{-13}$ \\
\hline
\end{tabular}


Computational Details. All ab initio calculations were carried out with OpenMOLCAS version $18.09^{6}$ and are of the CASSCF/RASSI type. The Cholesky decomposition threshold was set to $1 \times 10^{-8}$ to save disk space. An entire molecule was included, and the coordinates of atoms were extracted from the experimentally determined crystal structure. The neighbouring Dy(III) site was computationally replaced by the diamagnetic $\mathrm{Lu}(\mathrm{III})$ for complexes $\mathbf{2}$ and $\mathbf{3}$, and the low-spin $\mathrm{Fe}(\mathrm{III})$ is replaced by the $\mathrm{Ga}$ (III) for complex

2. Three ANO-RCC basis set approximations have been employed (see Table S6). ${ }^{7-9}$ Active space of the CASSCF method included nine electrons in seven $4 \mathrm{f}$ orbitals of Dy(III). 21 sextets for Dy(III) and 1 sextets + 12 quartets +40 doublets for $\mathrm{Fe}(\mathrm{III})$ were respectively optimized in state-averaged calculations and then mixed by spin-orbit coupling using RASSI approach. ${ }^{10}$ The $g$-tensors, energies, main magnetic axis as well as the magnetizations were obtained by SINGLE_ANISO routine ${ }^{11}$. Dipolar magnetic interactions were included within POLY_ANISO program (where the ab initio calculated $g$-factors for both of the low-spin $\mathrm{Fe}(\mathrm{III})$ ions are 2.00). ${ }^{12-14}$

Table S6. The employed ANO-RCC basis sets for complexes 1, 2 and 3.

\begin{tabular}{lll}
\hline $\mathbf{1}$ & $\mathbf{2}$ & $\mathbf{3}$ \\
\hline Dy.ANO-RCC-VTZP & Dy.ANO-RCC-VTZP & Dy.ANO-RCC-VTZP \\
O.ANO-RCC-VDZP & Lu.ANO-RCC-VTZP & Lu.ANO-RCC-VTZP \\
N.ANO-RCC-VDZP & Ga.ANO-RCC-VTZP & Co.ANO-RCC-VTZP \\
C.ANO-RCC-VDZ & Fe.ANO-RCC-VTZP & O.ANO-RCC-VDZP \\
H.ANO-RCC-VDZ & O.ANO-RCC-VDZP & N.ANO-RCC-VDZP \\
& N.ANO-RCC-VDZP & C.ANO-RCC-VDZ \\
& C.ANO-RCC-VDZ & H.ANO-RCC-VDZ \\
& H.ANO-RCC-VDZ & \\
\hline
\end{tabular}

Broken-symmetry (BS)-DFT calculations have been performed in ORCA 4.0.1.2 ${ }^{15}$ in order to estimate the magnetic exchange couplings between Dy and Fe, using the B3LYP/G functional with the SARC-DKH-TZVP basis set for the lanthanide, ${ }^{16}$ DKH-def2-TZVP basis set for the $\mathrm{Fe}$, and the def2-SVP basis set for all other atoms. Increased integration grids (Grid6) and VeryTight SCF convergence criteria were used. The scalar relativistic effects were considered by the second order Douglas-Kroll-Hess Hamiltonian. ${ }^{16}$ One of the Dy ions was substituted by Lu, and the other was replaced with the spin-only $\mathrm{Gd}$. To calculate the magnetic interaction between Dy and Fe, the magnetic interaction between $\mathrm{Gd}$ and Fe was rescaled to the spin of Dy. And we applied the Yamaguchi's formula to estimate the exchange coupling constants, $J=-\left(E_{\mathrm{HS}}-E_{\mathrm{BS}}\right) /\left(\left\langle S^{2}\right\rangle_{\mathrm{HS}}-\left\langle S^{2}\right\rangle_{\mathrm{BS}}\right)$, based on $\hat{H}_{\mathrm{HDVV}}=$ $-2 J \hat{S}_{\mathrm{Gd}} \hat{S}_{\mathrm{Fe}}$.

The calculations give the Dy-Fe magnetic exchange constants of $J_{\mathrm{Dy} 1-\mathrm{Fe} 1}=+0.13 \mathrm{~cm}^{-1}$ and $J_{\mathrm{Dy} 2-\mathrm{Fe} 2}$ $=+0.19 \mathrm{~cm}^{-1}$ (Note that there are two asymmetric units of $\{D y-F e-D y\}$ in the crystal structure, which are labelled as Dy1-Fe1-Dy1A and Dy2-Fe2-Dy2A), which have been both rescaled for the Lines model, $\hat{H}$ $=-J \hat{S}_{\mathrm{Dy}} \hat{S}_{\mathrm{Fe} .}{ }^{17}$ Concerning with the accuracy of BS-DFT calculations, the very small exchange coupling constants and the trend of magnetic susceptibilities, we ignored exchange coupling and only considered the dipolar interactions in the $\mathrm{Fe}_{2} \mathrm{Dy}$ complex (2). 
Table S7. Energies $(\mathrm{K}), g$-tensors $\left(g \mathrm{x}, g_{\mathrm{Y}}, g_{\mathrm{z}}\right.$ ) and angles $\left({ }^{\circ}\right)$ between the main magnetic axes of the lowest Kramers doublets for the local Dy(III) sites of complexes 1, 2 and $\mathbf{3}$.

\begin{tabular}{|c|c|c|c|c|c|c|c|c|c|c|c|c|c|c|c|}
\hline \multirow{2}{*}{ KD } & \multicolumn{3}{|c|}{1} & \multicolumn{3}{|c|}{ 2Dy1 } & \multicolumn{3}{|c|}{ 2Dy2 } & \multicolumn{3}{|c|}{ 3Dy1 } & \multicolumn{3}{|c|}{ 3Dy2 } \\
\hline & $E$ & $g$ & angle & $E$ & $g$ & angle & $E$ & $g$ & angle & $E$ & $g$ & angle & $E$ & $g$ & angle \\
\hline 1 & 0 & $\begin{array}{l}0.0014 \\
0.0017 \\
19.943\end{array}$ & 0 & 0 & $\begin{array}{c}0.0006 \\
0.0008 \\
19.961\end{array}$ & 0 & 0 & $\begin{array}{l}0.0006 \\
0.0008 \\
19.981\end{array}$ & 0 & 0 & $\begin{array}{l}0.0007 \\
0.0010 \\
19.959\end{array}$ & 0 & 0 & \begin{tabular}{|r}
0.0006 \\
0.0008 \\
19.9821
\end{tabular} & 0 \\
\hline 2 & 486.69 & $\begin{array}{l}0.0282 \\
0.0380 \\
16.997\end{array}$ & 1.2114 & 576.13 & $\begin{array}{c}0.0902 \\
0.1324 \\
16.950\end{array}$ & 3.1127 & 570.12 & $\begin{array}{l}0.0958 \\
0.1458 \\
16.972\end{array}$ & 3.2156 & 562.23 & $\begin{array}{c}0.1114 \\
0.1684 \\
16.940\end{array}$ & 4.6628 & 567.33 & \begin{tabular}{|r}
0.0995 \\
0.1488 \\
16.9808
\end{tabular} & 2.8253 \\
\hline 3 & 840.56 & $\begin{array}{l}0.3782 \\
0.5714 \\
13.926\end{array}$ & 1.0839 & 872.77 & $\begin{array}{c}2.4082 \\
5.4593 \\
12.678\end{array}$ & 53.399 & 847.92 & $\begin{array}{l}2.6295 \\
6.1100 \\
12.620\end{array}$ & 67.225 & 832.56 & $\begin{array}{l}2.2489 \\
4.0448 \\
14.385\end{array}$ & 61.269 & 845.67 & \begin{tabular}{|r}
2.5979 \\
6.1309 \\
12.6649
\end{tabular} & 70.865 \\
\hline 4 & 1031.46 & $\begin{array}{l}9.1122 \\
7.0198 \\
4.8236\end{array}$ & 81.433 & 957.45 & $\begin{array}{l}7.9803 \\
5.7788 \\
0.7506\end{array}$ & 34.576 & 927.06 & $\begin{array}{l}6.8459 \\
5.7967 \\
1.2168\end{array}$ & 38.180 & 921.40 & $\begin{array}{l}8.7374 \\
5.7716 \\
0.2588\end{array}$ & 41.106 & 922.16 & $\begin{array}{c}6.8626 \\
5.6732 \\
1.8238\end{array}$ & 43.693 \\
\hline 5 & 1134.36 & $\begin{array}{l}1.1492 \\
4.7213 \\
9.4711\end{array}$ & 83.705 & 1049.22 & $\begin{array}{c}0.4860 \\
3.1926 \\
13.653\end{array}$ & 80.906 & 1018.19 & $\begin{array}{l}0.2987 \\
4.7413 \\
12.985\end{array}$ & 86.549 & 1007.38 & $\begin{array}{l}1.6584 \\
2.9129 \\
12.125\end{array}$ & 78.873 & 1002.54 & \begin{tabular}{|r}
0.9978 \\
3.5186 \\
15.0154
\end{tabular} & 84.931 \\
\hline 6 & 1214.27 & $\begin{array}{l}2.4039 \\
2.8541 \\
9.9933\end{array}$ & 84.293 & 1075.42 & $\begin{array}{l}3.1931 \\
4.1626 \\
13.568\end{array}$ & 89.237 & 1054.05 & $\begin{array}{l}2.4931 \\
4.2705 \\
13.774\end{array}$ & 86.059 & 1034.81 & $\begin{array}{l}3.7325 \\
5.1400 \\
11.368\end{array}$ & 86.582 & 1038.10 & \begin{tabular}{|r}
2.4401 \\
3.5023 \\
13.8887
\end{tabular} & 82.387 \\
\hline 7 & 1237.82 & $\begin{array}{l}0.8836 \\
6.0597 \\
14.671\end{array}$ & 74.865 & 1153.78 & $\begin{array}{c}0.1243 \\
1.1657 \\
16.135\end{array}$ & 77.353 & 1128.56 & $\begin{array}{l}0.1853 \\
0.8813 \\
17.523\end{array}$ & 70.362 & 1119.69 & $\begin{array}{c}0.0342 \\
1.6214 \\
15.560\end{array}$ & 73.884 & 1105.27 & \begin{tabular}{|r}
0.2586 \\
1.0302 \\
17.3890
\end{tabular} & 68.790 \\
\hline 8 & 1291.25 & $\begin{array}{l}0.0593 \\
0.5543 \\
19.192\end{array}$ & 73.055 & $\mid 1203.87$ & $\begin{array}{r}0.2168 \\
1.0395 \\
17.3378\end{array}$ & 82.242 & 1195.12 & $\begin{array}{l}0.1731 \\
0.4332 \\
18.699\end{array}$ & 72.556 & 1174.06 & $\begin{array}{c}0.4210 \\
1.4432 \\
17.381\end{array}$ & 79.403 & 1176.61 & \begin{tabular}{|r}
0.1767 \\
0.4697 \\
18.5425
\end{tabular} & 71.082 \\
\hline
\end{tabular}


Table S8. LoProp charge analysis for the coordination sphere of Dy(III) in complexes 1, 2 and 3.

\begin{tabular}{|c|c|c|c|c|c|c|c|}
\hline & & 1 & & & & & \\
\hline $\mathrm{O} 3$ & & -0.9080 & & & & & \\
\hline $\mathrm{O} 2$ & & -0.6299 & & & & & \\
\hline N2 & & -0.3529 & & & & & \\
\hline N3 & & -0.3206 & & & & & \\
\hline Equatorialav & & -0.4345 & & & & & \\
\hline Axialav & & -0.9080 & & & & & \\
\hline & $2_{\text {Dy1 }}$ & & 2 Dy2 & & 3Dy1 & & 3Dy2 \\
\hline 01 & -0.9184 & O3 & -0.9092 & 01 & -0.9102 & $\mathrm{O} 3$ & -0.9077 \\
\hline $\mathrm{O} 2$ & -0.9095 & O4 & -0.9130 & $\mathrm{O} 2$ & -0.8971 & O4 & -0.9031 \\
\hline N1 & -0.3717 & N8 & -0.3618 & N1 & -0.3671 & N8 & -0.3602 \\
\hline N2 & -0.3215 & N9 & -0.3177 & N2 & -0.3228 & N9 & -0.3178 \\
\hline N3 & -0.3151 & N10 & -0.3154 & N3 & -0.3174 & N10 & -0.3150 \\
\hline N4 & -0.3644 & N11 & -0.3685 & N4 & -0.3678 & N11 & -0.3670 \\
\hline N5 & -0.5593 & N12 & -0.5640 & N5 & -0.5874 & N12 & -0.5808 \\
\hline Equatorialav $^{a v}$ & -0.3864 & Equatorialav & -0.3855 & Equatorialav & -0.3925 & Equatorialav & -0.3882 \\
\hline Axialav & -0.9140 & $A x i a l^{a v}$ & -0.9111 & Axial ${ }^{a v}$ & -0.9037 & Axial ${ }^{a v}$ & -0.9054 \\
\hline
\end{tabular}

Table S9. Crystal-field parameters on the crystal-field splitting for the local Dy(III) sites of 1, 2 and 3.

\begin{tabular}{|c|c|c|c|c|c|c|}
\hline \multirow[t]{16}{*}{1} & $k$ & $q$ & $B_{k}^{q}\left(\mathrm{~cm}^{-1}\right)$ & $k$ & $q$ & $B_{k}^{q}\left(\mathrm{~cm}^{-1}\right)$ \\
\hline & 2 & 0 & -4.792714633 & 6 & -6 & $-1.41789 E-06$ \\
\hline & 4 & 0 & -0.007851897 & 6 & -5 & 1.41703E-06 \\
\hline & 6 & 0 & 1.06678E-05 & 6 & -4 & 8.21364E-08 \\
\hline & 2 & -2 & -0.002023192 & 6 & -3 & $-1.36268 \mathrm{E}-07$ \\
\hline & 2 & -1 & -0.0146415 & 6 & -2 & $6.50131 \mathrm{E}-07$ \\
\hline & 2 & 1 & 0.260203186 & 6 & -1 & $3.02531 \mathrm{E}-07$ \\
\hline & 2 & 2 & 1.583340272 & 6 & 1 & 4.02262E-05 \\
\hline & 4 & -4 & 3.89518E-05 & 6 & 2 & 2.67438E-05 \\
\hline & 4 & -3 & $-3.99743 E-05$ & 6 & 3 & 0.000186992 \\
\hline & 4 & -2 & 1.61668E-05 & 6 & 4 & 0.00015231 \\
\hline & 4 & -1 & $-5.59046 E-05$ & 6 & 5 & 0.000141054 \\
\hline & 4 & 1 & -0.001318407 & 6 & 6 & 0.000246647 \\
\hline & 4 & 2 & 0.015199451 & & & \\
\hline & 4 & 3 & 0.027554021 & & & \\
\hline & 4 & 4 & -0.004204091 & & & \\
\hline \multirow[t]{9}{*}{$2_{\text {Dy1 }}$} & $k$ & $q$ & $B_{k}^{q}\left(\mathrm{~cm}^{-1}\right)$ & $k$ & $q$ & $B_{k}^{q}\left(\mathrm{~cm}^{-1}\right)$ \\
\hline & 2 & 0 & -3.907164229 & 6 & -6 & $1.92385 \mathrm{E}-06$ \\
\hline & 4 & 0 & -0.011757248 & 6 & -5 & 1.27189E-05 \\
\hline & 6 & 0 & 4.92841E-06 & 6 & -4 & $-1.04645 E-05$ \\
\hline & 2 & -2 & 0.306040763 & 6 & -3 & $2.27123 E-05$ \\
\hline & 2 & -1 & -0.949411026 & 6 & -2 & $-3.79634 \mathrm{E}-05$ \\
\hline & 2 & 1 & -0.092185493 & 6 & -1 & 1.52348E-05 \\
\hline & 2 & 2 & 1.427982955 & 6 & 1 & 7.66256E-05 \\
\hline & 4 & -4 & -0.001386479 & 6 & 2 & $-8.86909 \mathrm{E}-05$ \\
\hline
\end{tabular}




\begin{tabular}{|c|c|c|c|c|c|c|}
\hline & 4 & -3 & 0.003551258 & 6 & 3 & 0.000180944 \\
\hline & 4 & -2 & 0.002521824 & 6 & 4 & $-4.03525 E-05$ \\
\hline & 4 & -1 & 0.005579445 & 6 & 5 & -2.19921E-05 \\
\hline & 4 & 1 & -0.003315223 & 6 & 6 & 0.000191173 \\
\hline & 4 & 2 & 0.00099483 & & & \\
\hline & 4 & 3 & 0.022199944 & & & \\
\hline & 4 & 4 & -0.006826413 & & & \\
\hline \multirow[t]{16}{*}{2 Dy2 } & $k$ & $q$ & $B_{k}{ }^{q}\left(\mathrm{~cm}^{-1}\right)$ & $k$ & $q$ & $B_{k}{ }^{q}\left(\mathrm{~cm}^{-1}\right)$ \\
\hline & 2 & 0 & -3.798659857 & 6 & -6 & $-5.38079 E-05$ \\
\hline & 4 & 0 & -0.011561005 & 6 & -5 & 0.000139717 \\
\hline & 6 & 0 & 2.86849E-06 & 6 & -4 & $-4.71568 \mathrm{E}-06$ \\
\hline & 2 & -2 & -0.494989467 & 6 & -3 & -5.74987E-06 \\
\hline & 2 & -1 & -0.733359217 & 6 & -2 & 2.01508E-05 \\
\hline & 2 & 1 & 0.009039747 & 6 & -1 & 1.62855E-05 \\
\hline & 2 & 2 & 1.618745141 & 6 & 1 & 7.72535E-05 \\
\hline & 4 & -4 & 0.000505708 & 6 & 2 & -0.000103085 \\
\hline & 4 & -3 & -0.001570406 & 6 & 3 & 0.000182117 \\
\hline & 4 & -2 & 0.000267382 & 6 & 4 & $-3.02989 E-05$ \\
\hline & 4 & -1 & 0.003735003 & 6 & 5 & 2.00088E-05 \\
\hline & 4 & 1 & -0.003921474 & 6 & 6 & 0.000167298 \\
\hline & 4 & 2 & 0.001004825 & & & \\
\hline & 4 & 3 & 0.021287558 & & & \\
\hline & 4 & 4 & -0.006069389 & & & \\
\hline \multirow[t]{16}{*}{ 3Dy1 } & $k$ & $q$ & $B_{k}^{q}\left(\mathrm{~cm}^{-1}\right)$ & $k$ & $q$ & $B_{k}^{q}\left(\mathrm{~cm}^{-1}\right)$ \\
\hline & 2 & 0 & -3.714908775 & 6 & -6 & $-2.09088 \mathrm{E}-05$ \\
\hline & 4 & 0 & -0.011680319 & 6 & -5 & 1.42567E-05 \\
\hline & 6 & 0 & 4.58384E-06 & 6 & -4 & $-9.73102 E-06$ \\
\hline & 2 & -2 & 0.183872095 & 6 & -3 & 2.97002E-05 \\
\hline & 2 & -1 & -1.314192603 & 6 & -2 & $-3.82993 E-05$ \\
\hline & 2 & 1 & 0.01484039 & 6 & -1 & 3.40565E-05 \\
\hline & 2 & 2 & 1.491258796 & 6 & 1 & 4.58384E-06 \\
\hline & 4 & -4 & -0.001109962 & 6 & 2 & 7.01035E-05 \\
\hline & 4 & -3 & 0.003952996 & 6 & 3 & $-8.9235 \mathrm{E}-05$ \\
\hline & 4 & -2 & 0.00268587 & 6 & 4 & 0.000186381 \\
\hline & 4 & -1 & 0.007096254 & 6 & 5 & $-3.03066 \mathrm{E}-05$ \\
\hline & 4 & 1 & -0.003612264 & 6 & 6 & $-3.32493 E-05$ \\
\hline & 4 & 2 & 0.001333677 & & & \\
\hline & 4 & 3 & 0.023621682 & & & \\
\hline & 4 & 4 & -0.005982496 & & & \\
\hline \multirow[t]{6}{*}{ 3y2 } & $k$ & $q$ & $B_{k}{ }^{q}\left(\mathrm{~cm}^{-1}\right)$ & $k$ & $q$ & $B_{k}{ }^{q}\left(\mathrm{~cm}^{-1}\right)$ \\
\hline & 2 & 0 & -3.717115065 & 6 & -6 & $-7.51358 E-05$ \\
\hline & 4 & 0 & -0.011643602 & 6 & -5 & 0.000130619 \\
\hline & 6 & 0 & 3.3904E-06 & 6 & -4 & $-2.16945 E-06$ \\
\hline & 2 & -2 & -0.552531533 & 6 & -3 & $-2.22463 \mathrm{E}-05$ \\
\hline & 2 & -1 & -0.683057919 & 6 & -2 & $2.51601 \mathrm{E}-05$ \\
\hline
\end{tabular}




\begin{tabular}{rrrrrr}
\hline 2 & 1 & 0.091617165 & 6 & -1 & $1.21445 \mathrm{E}-05$ \\
2 & 2 & 1.429392189 & 6 & 1 & $7.41063 \mathrm{E}-05$ \\
4 & -4 & 0.000959977 & 6 & 2 & $-9.58862 \mathrm{E}-05$ \\
4 & -3 & -0.003008873 & 6 & 3 & 0.000172293 \\
4 & -2 & 0.000256647 & 6 & 4 & $-2.70856 \mathrm{E}-05$ \\
4 & -1 & 0.00359404 & 6 & 5 & $2.15621 \mathrm{E}-05$ \\
4 & 1 & -0.00431372 & 6 & 6 & 0.000174857 \\
4 & 2 & 0.001199274 & & & \\
4 & 3 & 0.019822041 & & & \\
4 & 4 & -0.00558723 & & & \\
\hline
\end{tabular}

$\hat{H}=\sum B_{k}{ }^{q} \hat{O}_{k}{ }^{q}$, where $\hat{O}_{k}{ }^{q}$ is the extended Steven operators.

Table S10. Energies $(\mathrm{K})$ and the relative thermally assisted quantum tunnelling rate at $60 \mathrm{~K}$ between the $i^{\text {th }}$ Kramers doublets and the ground one $\left(\Gamma_{i \pm} / \Gamma_{1 \pm}\right)$ for the local Dy(III) sites of complexes 1, 2 and $\mathbf{3}$. Two of the largest are labelled as red.

\begin{tabular}{|c|c|c|c|c|c|c|c|c|c|c|}
\hline \multirow{2}{*}{ KD } & \multicolumn{2}{|c|}{1} & \multicolumn{2}{|c|}{ 2Dy1 } & \multicolumn{2}{|c|}{ 2Dy2 } & \multicolumn{2}{|c|}{ 3Dy1 } & \multicolumn{2}{|c|}{ 3Dy2 } \\
\hline & $E$ & $\Gamma_{i \pm} / \Gamma_{1 \pm}$ & $E$ & $\Gamma_{i \pm} / \Gamma_{1 \pm}$ & $E$ & $\Gamma_{i \pm} / \Gamma_{1 \pm}$ & $E$ & $\Gamma_{i \pm} / \Gamma_{1 \pm}$ & $E$ & $\Gamma_{i \pm} / \Gamma_{1 \pm}$ \\
\hline 1 & 0 & 1.00 & 0 & 1.00 & 0 & 1.00 & 0 & 1.00 & 0 & 1.00 \\
\hline 2 & 486.69 & 0.14 & 576.13 & 1.70 & 570.12 & 2.29 & 562.23 & 2.30 & 567.33 & 2.53 \\
\hline 3 & 840.56 & 0.08 & 872.77 & 26.01 & 847.92 & 64.80 & 832.56 & 30.74 & 845.67 & 73.59 \\
\hline 4 & 1031.46 & 0.72 & 957.45 & 3.05 & 927.06 & 7.65 & 921.40 & 2.84 & 922.16 & 9.01 \\
\hline 5 & 1134.36 & 0.09 & 1049.22 & 1.32 & 1018.19 & 7.01 & 1007.38 & 2.43 & 1002.54 & 10.76 \\
\hline 6 & 1214.27 & 0.03 & 1075.42 & 3.08 & 1054.05 & 4.21 & 1034.81 & 3.23 & 1038.10 & 4.63 \\
\hline 7 & 1237.82 & 0.01 & 1153.78 & 0.05 & 1128.56 & 0.01 & 1119.69 & 0.05 & 1105.27 & 0.02 \\
\hline 8 & 1291.25 & 0.00 & 1203.87 & 0.04 & 1195.12 & 0.00 & 1174.06 & 0.05 & 1176.61 & 0.00 \\
\hline
\end{tabular}


Table S11. Energies $(\mathrm{K})$ and $g$-tensors $\left(g \mathrm{x}, g_{\mathrm{Y}}, g_{\mathrm{Z}}\right)$ of the 4 lowest exchange doublets of complex 2.

\begin{tabular}{|c|c|c|c|c|}
\hline & \multicolumn{2}{|c|}{ Dy1-Fe1-Dy1A } & \multicolumn{2}{|c|}{ Dy2-Fe2-Dy2A } \\
\hline KD & E & $g$ & E & $g$ \\
\hline \multirow{3}{*}{1} & & 2.0019 & \multirow{3}{*}{0} & 2.0018 \\
\hline & 0 & 2.0023 & & 2.0024 \\
\hline & & 2.0031 & & 2.0031 \\
\hline \multirow{3}{*}{2} & \multirow{3}{*}{0} & 2.0019 & \multirow{3}{*}{0} & 2.0018 \\
\hline & & 2.0023 & & 2.0024 \\
\hline & & 2.0031 & & 2.0031 \\
\hline \multirow{3}{*}{3} & \multirow{3}{*}{0.0191} & 0.0000 & \multirow{3}{*}{0.0164} & 0.0000 \\
\hline & & 0.0000 & & 0.0000 \\
\hline & & 37.9192 & & 38.0255 \\
\hline \multirow{3}{*}{4} & \multirow{3}{*}{0.1741} & 0.0000 & \multirow{3}{*}{0.1743} & 0.0000 \\
\hline & & 0.0000 & & 0.0000 \\
\hline & & 41.9238 & & 41.9049 \\
\hline
\end{tabular}

Note: There are two asymmetric units of $\{D y-F e-D y\}$ in the crystal structure, which are labelled as Dy1-Fe1-Dy1A and Dy2-Fe2-Dy2A.

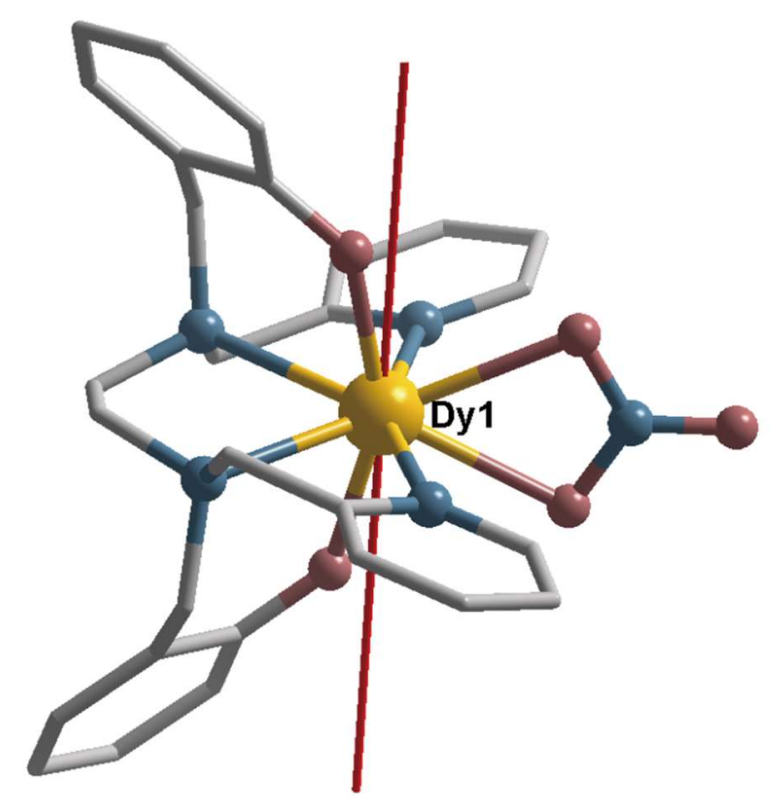

Figure S25. Molecular structure for 1 with the orientation of the main magnetic axis of the ground Kramers doublet (red line). Color code: Dy, yellow; O, red; N, blue; C, gray. 

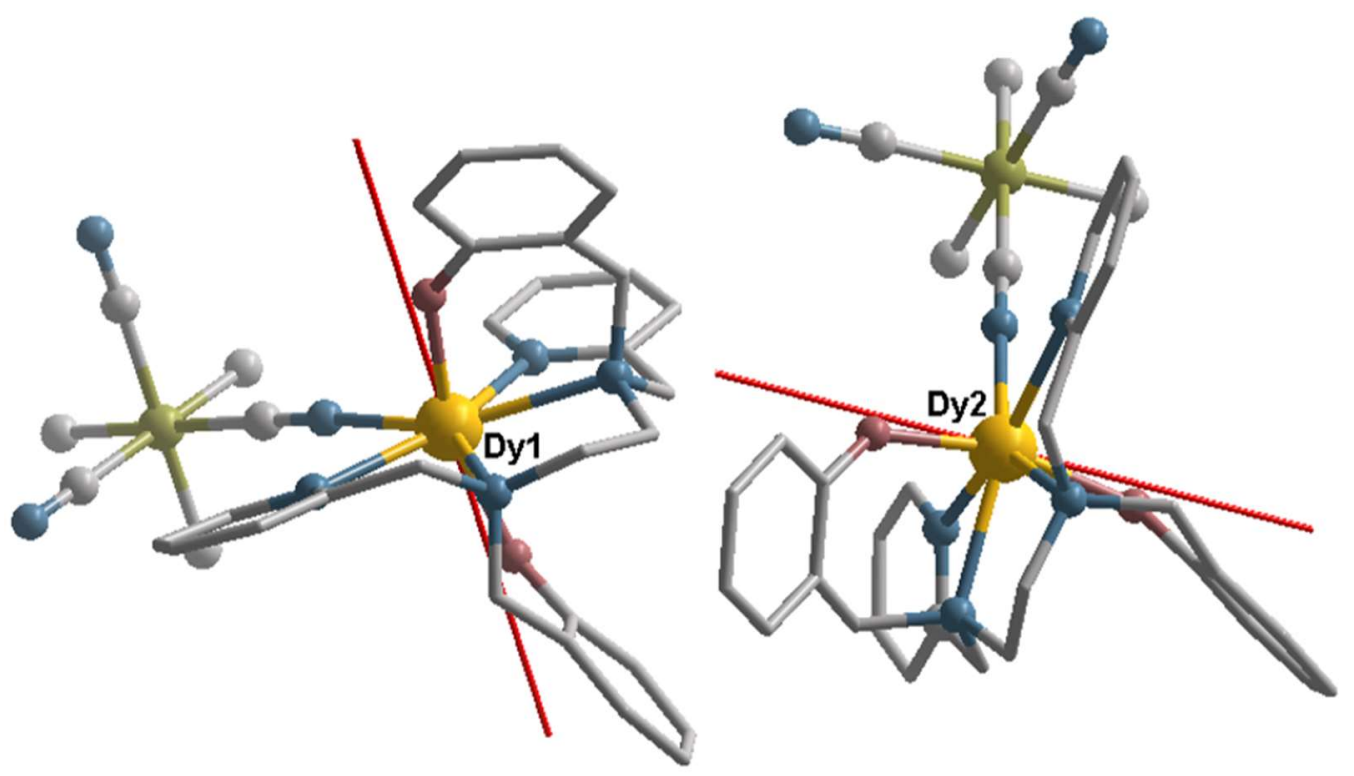

Figure S26. Molecular structure for $\mathbf{2}$ with the orientation of the main magnetic axis of the ground Kramers doublet (red lines). Color code: Dy, yellow; Fe, green; O, red; N, blue; C, gray.
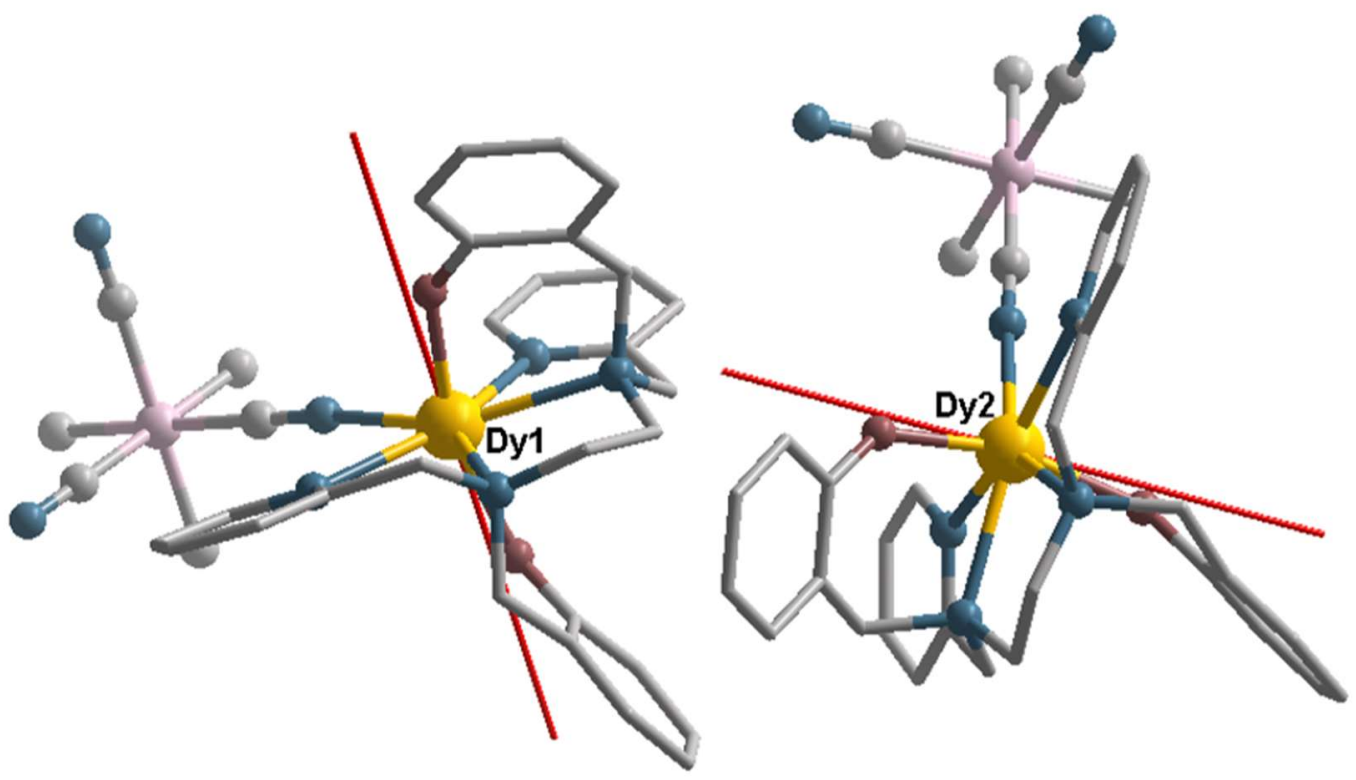

Figure S27. Molecular structure for $\mathbf{3}$ with the orientation of the main magnetic axis of the ground Kramers doublet (red lines). Color code: Dy, yellow; Co, pink; O, red; N, blue; C, gray. 


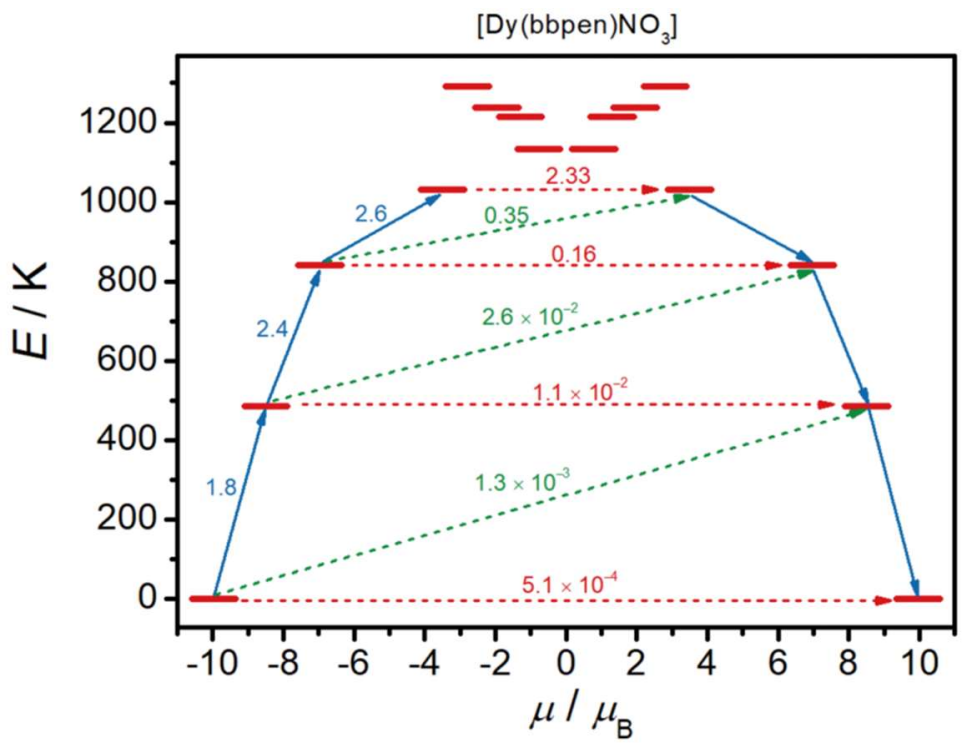

Figure S28. Magnetization blocking barriers for 1 . The lowest 16 spin-orbit states are arranged according to the magnitude of their magnetic moments on the $x$ axis (bold horizontal red lines). The numbers next to arrows connecting two states display the average transition magnetic moment matrix element between the respective states.
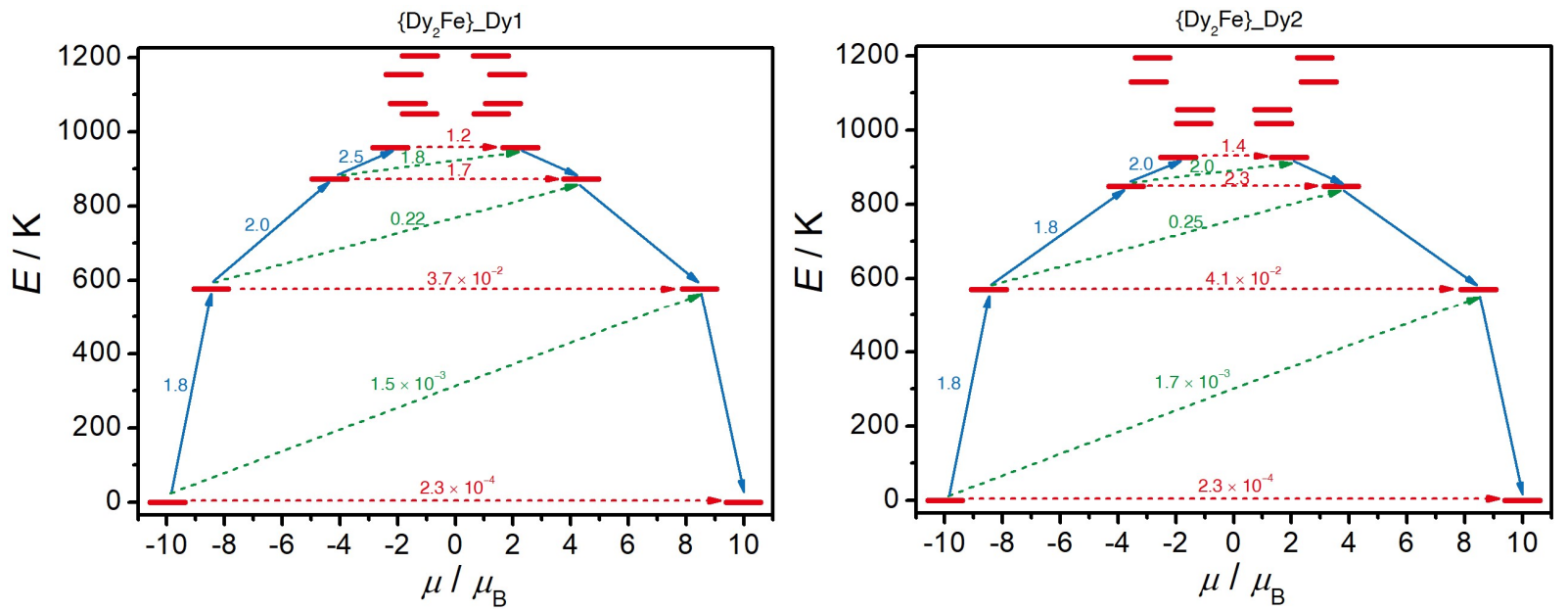

Figure S29. Magnetization blocking barriers for 2, respectively for the site Dy1 (left) and site Dy2 (right). The lowest 16 spin-orbit states are arranged according to the magnitude of their magnetic moments on the $x$ axis (bold horizontal red lines). The numbers next to arrows connecting two states display the average transition magnetic moment matrix element between the respective states. 

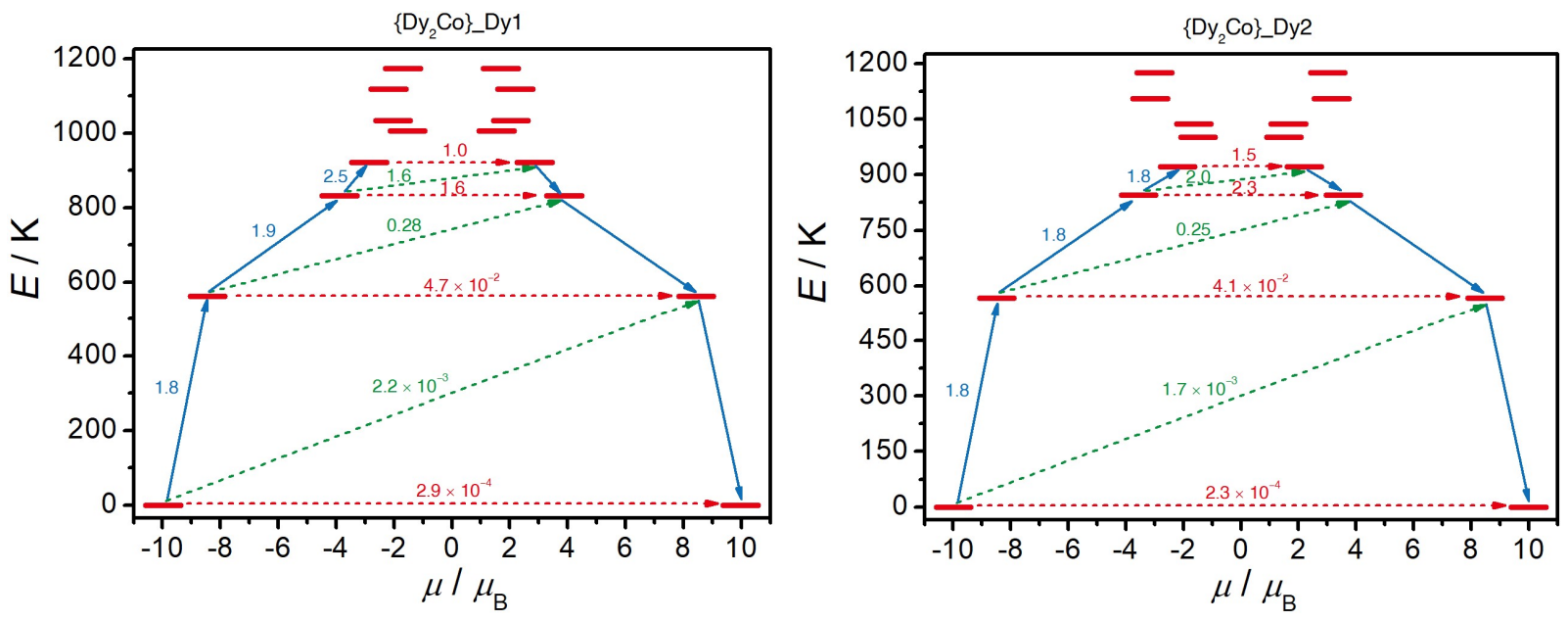

Figure S30. Magnetization blocking barriers for 3 , respectively for the site Dy1 (left) and Dy2 (right). The lowest 16 spin-orbit states are arranged according to the magnitude of their magnetic moments on the $x$ axis (bold horizontal red lines). The numbers next to arrows connecting two states display the average transition magnetic moment matrix element between the respective states.
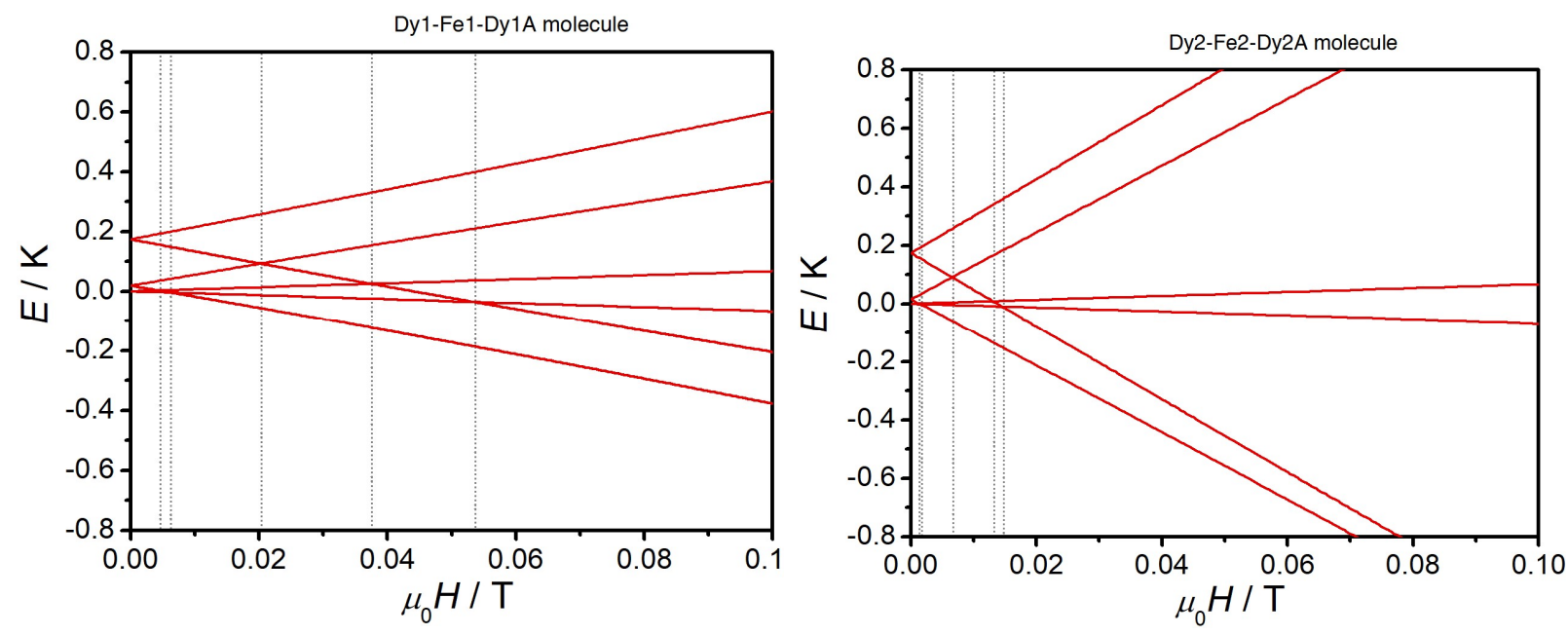

Figure S31. Zeeman splitting along the magnetic anisotropy axis for two $\{\mathrm{Dy} 2 \mathrm{Fe}\}$ molecules in complex 2, respectively for the $\{\mathrm{Dy} 1-\mathrm{Fe} 1-\mathrm{Dy} 1 \mathrm{~A}\}$ (left) and the $\{\mathrm{Dy} 2-\mathrm{Fe} 2-\mathrm{Dy} 2 \mathrm{~A}\}$ (right). The simulations are based on the CASSCF/SO-RASSI/SINGLE_ANISO calculations with magnetic dipolar interactions on POLY_ANISO. The gray dash lines represent the intersections between the exchange states. 

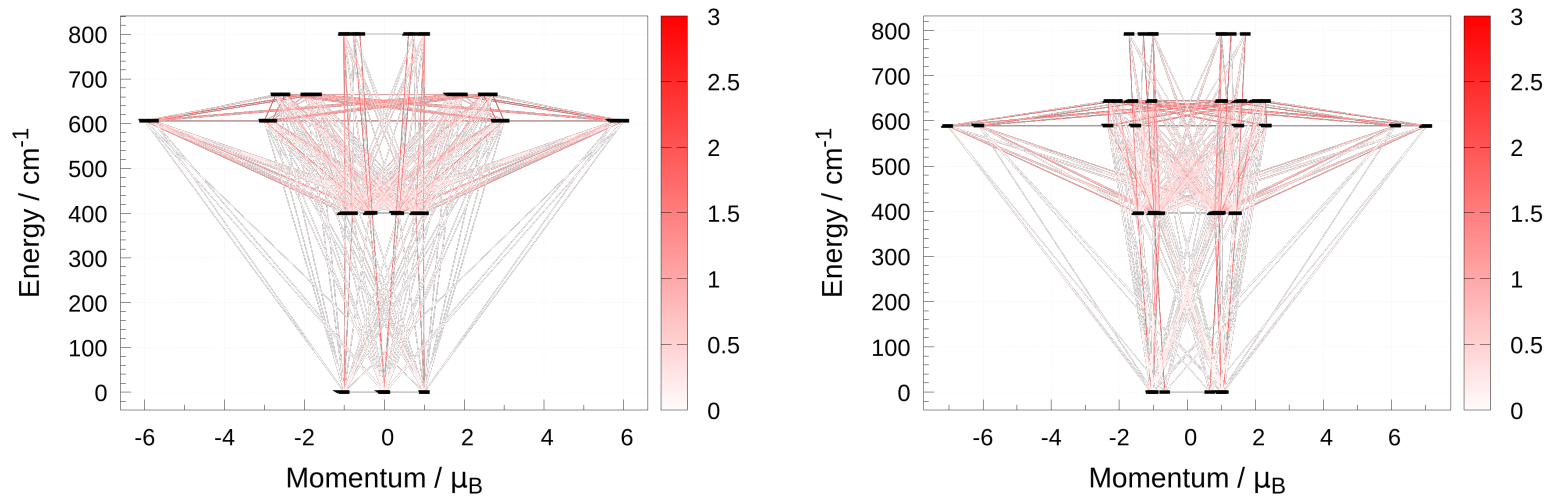

Figure S32. Magnetization blocking barriers for two $\left\{\mathrm{Dy}_{2} \mathrm{Fe}\right\}$ molecules in complex 2, respectively for the \{Dy1-Fe1-Dy1A (left) and the \{Dy2-Fe2-Dy2A $\}$ (right). The 32 lowest exchange doublets are selected herein. The values of the average transition magnetic moment matrix elements are highlighted as the color depth of red lines obtained from POLY_ANISO. 


\section{References}

1. Alvarez, S.; Alemany, P.; Casanova, D.; Cirera, J.; Llunell, M.; Avnir, D. Shape maps and polyhedral interconversion paths in transition metal chemistry. Coord. Chem. Rev. 2005, 249 (17), 1693-1708.

2. Casanova, D.; Llunell, M.; Alemany, P.; Alvarez, S. The Rich Stereochemistry of Eight-Vertex Polyhedra: A Continuous Shape Measures Study. Chem. Eur. J. 2005, 11 (5), 1479-1494.

3. (a) Giansiracusa, M. J.; Moreno-Pineda, E.; Hussain, R.; Marx, R.; Martínez Prada, M.; Neugebauer, P.; Al-Badran, S.; Collison, D.; Tuna, F.; van Slageren, J.; Carretta, S.; Guidi, T.; McInnes, E. J. L.; Winpenny, R. E. P.; Chilton, N. F. Measurement of Magnetic Exchange in Asymmetric Lanthanide Dimetallics: Toward a Transferable Theoretical Framework. J. Am. Chem. Soc. 2018, 140 (7), 2504-2513. (b) Perfetti, M.; Gysler, M.; Rechkemmer-Patalen, Y.; Zhang, P.; Taştan, H.; Fischer, F.; Netz, J.; Frey, W.; Zimmermann, L. W.; Schleid, T.; Hakl, M.; Orlita, M.; Ungur, L.; Chibotaru, L.; Brock-Nannestad, T.; Piligkos, S.; van Slageren, J. Determination of the electronic structure of a dinuclear dysprosium single molecule magnet without symmetry idealization. Chem. Sci. 2019, 10 (7), 2101-2110.

4. (a) Marx, R.; Moro, F.; Dörfel, M.; Ungur, L; Waters, M.; Jiang, S.-D.; Orlita, M.; Taylor, J.; Frey, W., Chibotaru, L. F.; van Slageren, J. Spectroscopic determination of crystal field splittings in lanthanide double deckers. Chem. Sci. 2014, 5 (8), 3287-3293. (b) Langley, S. K.; Wielechowski, D. P.; Vieru, V.; Chilton, N. F.; Moubaraki, B.; Chibotaru, L. F.; Murray, K. S. Modulation of slow magnetic relaxation by tuning magnetic exchange in \{Cr2Dy2\} single molecule magnets. Chem. Sci. 2014, 5 (8), 3246-3256.

5. Liu, J.-L.; Chen, Y.-C.; Tong, M.-L. Symmetry strategies for high performance lanthanide-based single-molecule magnets. Chem. Soc. Rev. 2018, 47 (7), 2431-2453.

6. Aquilante, F.; Autschbach, J.; Carlson, R. K.; Chibotaru, L. F.; Delcey, M. G.; De Vico, L.; Fdez. Galván, I.; Ferré, N.; Frutos, L. M.; Gagliardi, L.; Garavelli, M.; Giussani, A.; Hoyer, C. E.; Li Manni, G.; Lischka, H.; Ma, D.; Malmqvist, P. A.; Müller, T.; Nenov, A.; Olivucci, M.; Pedersen, T. B.; Peng, D.; Plasser, F.; Pritchard, B.; Reiher, M.; Rivalta, I.; Schapiro, I.; Segarra-Martí, J.; Stenrup, M.; Truhlar, D. G.; Ungur, L.; Valentini, A.; Vancoillie, S.; Veryazov, V.; Vysotskiy, V. P.; Weingart, O.; Zapata, F.; Lindh, R. Molcas 8: New capabilities for multiconfigurational quantum chemical calculations across the periodic table. $J$. Comput. Chem. 2016, 37 (5), 506-541.

7. Roos, B. O.; Lindh, R.; Malmqvist, P.-Å.; Veryazov, V.; Widmark, P.-O.; Borin, A. C. New Relativistic Atomic Natural Orbital Basis Sets for Lanthanide Atoms with Applications to the Ce Diatom and LuF3. J. Phys. Chem. A 2008, 112 (45), 11431-11435.

8. Roos, B. O.; Lindh, R.; Malmqvist, P.-Å.; Veryazov, V.; Widmark, P.-O. Main group atoms and dimers studied with a new relativistic ANO basis set. J. Phys. Chem. A 2004, 108 (15), 2851-2858.

9. Roos, B. O.; Lindh, R.; Malmqvist, P.-Å.; Veryazov, V.; Widmark, P.-O. New Relativistic ANO Basis Sets for Transition Metal Atoms. J. Phys. Chem. A 2005, 109 (29), 6575-6579.

10. Malmqvist, P. Å.; Roos, B. O.; Schimmelpfennig, B. The restricted active space (RAS) state interaction approach with spin-orbit coupling. Chem. Phys. Lett. 2002, 357 (3), 230-240.

11. Chibotaru, L. F.; Ungur, L. Ab initio calculation of anisotropic magnetic properties of complexes. I. Unique definition of pseudospin Hamiltonians and their derivation. J. Chem. Phys. 2012, 137 (6), 064112.

12. Chibotaru, L. F.; Ungur, L.; Soncini, A. The Origin of Nonmagnetic Kramers Doublets in the Ground State of Dysprosium Triangles: Evidence for a Toroidal Magnetic Moment. Angew. Chem. Int. Ed. 2008, 47 (22), 4126-4129.

13. Ungur, L.; Van den Heuvel, W.; Chibotaru, L. F. Ab initio investigation of the non-collinear magnetic structure and the lowest magnetic excitations in dysprosium triangles. New J. Chem. 2009, 33 (6), 1224-1230. 
14. Chibotaru, L. F.; Ungur, L.; Aronica, C.; Elmoll, H.; Pilet, G.; Luneau, D. Structure, Magnetism, and Theoretical Study of a Mixed-Valence Coll3Colll4 Heptanuclear Wheel: Lack of SMM Behavior despite Negative Magnetic Anisotropy. J. Am. Chem. Soc. 2008, 130 (37), 12445-12455.

15. Neese, F. The ORCA program system. Wiley Interdiscip. Rev.: Comput. Mol. Sci. 2012, 2, 73-78.

16. Pantazis, D. A.; Neese, F. All-Electron Scalar Relativistic Basis Sets for the Lanthanides. J. Chem. Theory Comput. 2009, 5, 2229-2238.

17. M. E. Lines. Orbital angular momentum in the theory of paramagnetic clusters. J. Chem. Phys. 1971, 55 (6), 2977-2984. 